\title{
On $(1,2)^{*}$-Fuzzy Soft $b$-Continuity in Fuzzy Soft Bitopological Spaces
}

\author{
A. F. Sayed * \\ Mathematics Department, Al-Lith University College, Umm Al-Qura University \\ P.O. Box 112, Al-Lith 21961, Makkah Al Mukarramah, Kingdom of Saudi Arabia
}

February 21, 2021

\begin{abstract}
The purpose of this paper is to introduce the concepts of $(1,2)^{*}$-fuzzy soft $b$ continuous maps, $(1,2)$-fuzzy soft $b$-irresolute maps and the relations with other weak forms of fuzzy soft continuous maps in fuzzy soft bitopological spaces. Also we introduce and investigate the basic properties of $(1,2) *$-fuzzy soft $b$-irresolutemap and $(1,2) *$-fuzzy soft $b$-open (closed) maps.
\end{abstract}

Keywords and phrases: $(1,2) *$-fuzzy soft $b$-continuous, $(1,2)^{*}$-fuzzy soft $b$-irresolute, $(1,2)^{*}-$ fuzzy soft $b$-open map, $(1,2)^{*}$-fuzzy soft $b$-closed map.

2010 Mathematics Subject Classification: 54A05, 54A40, 54F99

\section{Introduction}

In the year 1965, Zadeh [30], introduced the concept of fuzzy set theory and its applications that can be found in many branches of mathematical and engineering sciences including management science, control engineering, computer science, artificial intelligence (see, [6], [7]).

In the year 1999, Russian researcher Molodtsov [16], initiated the concept of soft sets as a new mathematical tool to deal with uncertainties while modeling problems in engineering physics, computer science, economics, social sciences and medical sciences (see, [17], [29]. In 2003, Maji et al. [15], studied the theory of soft sets initiated by Molodtsov. They defined equality of two soft sets, subset and super set of a soft set, complement of a soft set, null soft set and absolute soft set with examples. Soft binary operations like AND, OR and also the operations of union and intersection were also defined. In 2005, Chen [5], presented a new definition of soft set parametrization reduction and a comparison ofit with attribute reduction in rough set theory.

*E-mail address: dr.afsayed@hotmail.com, afssayed@uqu.edu.sa 
In 1963, Kelly [11], first initiated the concept of bitopological spaces and other authors have contributed to development and construction some of properties of such spaces (see, [12], [20])as a generalizations of which are in general topology.

In 2014, Ittanagi [8], introduced and studied the concept of soft bitopological spaces and other authors have contributed to development and construction some properties of such spaces (see, [9], [10], [21], [22]).

The notion of soft bitopological space was introduced using different soft topologies on an initial universe set. On the other hand, the mixed type of soft set theory was given using different soft topologies (see, [28], [1], [2], [18]).

In 2015, Mukherjee1 and Park [19] first introduced the notion of fuzzy soft bitopological space and they introduced the notions of $\tau_{1} \tau_{2}$-fuzzy soft open (closed) sets, $\tau_{1} \tau_{2}$-fuzzy soft interior (resp. closure and studied some of their basic properties. Also, my works ([25], [26], [27]) were extension and continuation of studying in this trend by character- izing a new type of fuzzy soft sets and introducing some separation axioms in fuzzy soft bitopological spaces. The purpose of this paper is to The purpose of this paper is to introduce the concepts of $(1,2)^{*}$-fuzzy soft $b$-continuous maps, $(1,2)^{*}$-fuzzy soft $b$-irresolute maps and the relations with other weak forms of fuzzy soft continuous maps in fuzzy soft bitopological spaces. Also we introduce and investigate the basic properties of $(1,2)^{*}$ - fuzzy soft $b$-irresolute map and $(1,2)^{*}$-fuzzy soft $b$-open (closed) maps.

\section{Preliminaries}

In this section we are going to present the basic definitions and results of fuzzy soft set and fuzzy soft bitopological space which will be a central role in our paper.

Throughout our discussion, $X$ refers to an initial universe, $E$ the set of all parameters for $X$ and $P(X)$ denotes the power set of $X$.

Definition 2.1 [30] A fuzzy set $A$ in a non-empty set $X$ is characterized by a membership function $\mu_{A}: X \rightarrow[0,1]=I$ whose value $\mu_{A}(x)$ represents the "degree of membership" of $x$ in A for every $x$ in $X$. Let $I^{X}$ denotes the family of all fuzzy sets on $X$.

A member $A$ in $I^{X}$ is contained in a member $B$ of $I^{X}$ denoted $A \leq B$ if and only if $\mu_{A}(x) \leq \mu_{B}(x)$ for every $x \in X$ (see [30]).

Let $A, B \in I^{X}$, we have the following properties on fuzzy sets (see [30]).

(1) Equality: $A=B$ if and only if $\mu_{A}(x)=\mu_{B}(x)$ for all $x \in X$,

(2) Intersction: $C=A \wedge B \in I^{X}$ by $\mu_{C}(x)=\min \left\{\mu_{A}(x), \mu_{B}(x)\right\}$ for all $x \in X$,

(3) Union: $D=A \vee B \in I^{X}$ by $\mu_{C}(x)=\max \left\{\mu_{A}(x), \mu_{B}(x)\right\}$ for all $x \in X$,

(4) Complement: $E=A^{c} \in I^{X}$ by $\mu E(x)=1-\mu_{A}(x)$ for all $x \in X$ 
Definition 2.2 [30] The empty fuzzy set on $X$ denoted by $\widetilde{0}$ is a function which maps each $x \in X$ to 0 . That is, $\widetilde{0}(x)=0$ for all $x \in X$.

$A$ universal fuzzy set denoted by $\widetilde{1}$ is a function which maps each $x \in X$ to 1 . That is, $\tilde{1}(x)=1$ for all $x \in X$.

Definition 2.3 [16] Let $A \subseteq E$. A pair $(F, A)$ is called a soft set over $X$ if $F$ is a mapping $F: A \rightarrow P(X)$.

Definition 2.4 [14] Let $A \subseteq E$. A pair $(f, A)$, denoted by $f_{A}$, is called a fuzzy soft set over $X$, where $f$ is a mapping given by $f: A \rightarrow I^{X}$ defined by $f_{A}(e)=\mu_{f_{A}}^{e}$ where $\mu_{f_{A}}^{e}=\begin{array}{ll}\widetilde{0}, & \text { if } e \not t A ; \\ \text { otherwise, } & \text { if } e \in A .\end{array}$

$\widetilde{(X, E)}$ denotes the family of all fuzzy soft sets over $(X, E)$.

Definition 2.5 [15] A fuzzy soft set $f_{A} \tilde{\in}(\overline{X, E})$ is said to be:

(a) NULL fuzzy soft set, denoted by $\tilde{\varphi}$, if for all $e \in A, f_{A}(e)=\widetilde{0}$.

(b) absolute fuzzy soft set, denoted by $\tilde{E}$, if for all $e \in E, f_{A}(e)=\tilde{1}$.

Definition 2.6 [24] The complement of a fuzzy soft set $f_{A}$, denoted by $f_{A}^{c}$ where $f_{A}^{c}$ : $E \rightarrow I^{X}$ is a mapping given by $\mu_{f_{A}^{c}}^{e}=\tilde{1}-\mu_{f_{A}}^{e}$, for all $e \in E$ and where $\tilde{1}(x)=1$, for all $x \in X$. Clearly $\left(f^{c}\right)^{c}=f_{A}$.

Definition 2.7 [24] Let $f_{A}, g_{B} \in(\overline{X, E}) . f_{A}$ is fuzzy soft subset of $g_{B}$, denoted by $f_{A} \tilde{\subseteq} g_{B}$, if $A \subseteq B$ and $\mu_{f_{A}} \leq \mu_{g_{B}}^{e}$ for all $e \in A$, i.e. $\mu_{f_{A}}^{e}(x) \leq \mu_{g_{B}}^{e}(x)$ for all $x \in X$ and for all $e \in A$.

Definition 2.8 [24] Let $f_{A}, g_{B} \tilde{\in}(\overline{X, E})$. The union of $f_{A}$ and $g_{B}$ is also a fuzzy soft set $h_{C}$, where $C=A \cup B$ and for all $e \in C, h_{C}(e)=\mu_{h_{c}}=\mu_{f_{A}}^{e} \vee \mu_{g_{B}}^{e}$. Here we write $h_{C}=f_{A} \tilde{\cup}$

Definition 2.9 [24] Let $\boldsymbol{f}_{A}, g_{B} \widetilde{\in}(\overline{X, E})$. The intersection of $\boldsymbol{f}_{A}$ and $g_{B}$ is also a fuzzy soft set $d c$, where $C=A \cap B$ and for all $e \in C, d c(e)=\mu_{d_{c}}^{e}=\mu_{f_{A}}^{e} \wedge \mu_{g_{B}}^{e}$. Here we write 
Bulletin of the

\section{Korean Nathematical Society}

ISSN 1015-8634 (Print) ISSN22343016(Onine)

$d_{C}=f_{A} \tilde{\cap} g_{B}$.

Definition 2.10 [13] The fuzzy soft set $\boldsymbol{f}_{A} \widetilde{\in}(\overline{\boldsymbol{X}, E})$ is called fuzzy soft point if there exist $x \in X$ and $e \in E$ such that $\mu_{A}^{e}(x)=\alpha(0<\alpha \leq 1)$ and $\mu_{A}^{e}(y)=0$ for each $y \in X-\{x\}$, and this fuzzy soft point is denoted by $y_{a} x^{e}$ orf $f_{e}$.

Definition 2.11 [13] The fuzzy soft point $f_{e}$ is said to be belonging to the fuzzy soft set $(g, A)$, denoted by $f_{e} \tilde{\epsilon}(g, A)$, if for the element $e \in A, \alpha \leq \mu_{g_{A}}(x)$, (0Definition 2.12 [4] Let $\boldsymbol{f}_{A}$ be fuzzy soft set over $X$. The two fuzzy soft points $\boldsymbol{f}_{e_{1}}, \boldsymbol{f}_{e_{2}} \tilde{f} f_{A}$ are said to be equal if $\mu_{f_{e_{1}}}(x)=\mu f_{e_{2}}(x)$ for all $x \in X$. Thus $f_{e_{1}} \neq f_{e_{2}}$ if and only $\mu_{e_{e_{1}}}(x) /=\mu_{f_{e_{2}}}(x)$ for all $x$ $\in X$.

Definition 2.13 [24] A fuzzy soft topology $\tau$ over $(X, E)$ is a family of fuzzy soft sets over $(X, E)$ satisfying the following properties:

(i) $\widetilde{0}_{E}, \widetilde{1}_{E} \in \tau$

(ii) if $\boldsymbol{f}_{A}, g_{B} \in \tau$, then $\boldsymbol{f}_{A} \tilde{\cap}_{g_{B}} \in \tau$,

(iii) if $f_{A_{a}} \in \tau$ for all $\alpha \in \Delta$ an index set, then ${ }^{\sim}{ }_{\alpha \in \Delta} f_{A_{a}} \in \tau$.

Definition 2.14 [19] If $\tau$ is a fuzzy soft topology on $(X, E)$ the triple $(X, E, \tau)$ is said to be a fuzzy soft topological space. Also each member of $\tau$ is called a fuzzy soft open set in $(X$, $E, \tau)$.

The complement of a fuzzy soft open set is a fuzzy soft closed set.

Definition 2.15 [19] Let $\left(X, E, \tau_{1}\right)$ and $\left(X, E, \tau_{2}\right)$ be the two different fuzzy soft topolo- gies on $(X, E)$. Then $\left(X, E, \tau_{1}, \tau_{2}\right)$ is called a fuzzy soft bitopological space on which no seperation axioms are assumed unless explicitly stated.

The members of $\tau_{i}(i=1,2)$ are called $\tau_{i}(i=1,2)$-fuzzy soft open sets and the complement of $\tau_{i}(i=1,2)$ - fuzzy soft open sets are called $\tau_{i}(i=1,2)$-fuzzy soft closed sets.

Definition 2.16 [19] A fuzzy soft set $f_{E} \widetilde{\in}(\overline{X, E})$ is called $\tau_{1} \tau_{2}$-fuzzy soft open set if $f_{E}=g_{E} \widetilde{\cup} h_{E}$ such that $g_{E} \tilde{\in} \tau_{1}$ and $h_{E} \tilde{\in} \tau_{2}$.

The complement of $\tau_{1} \tau_{2}$-fuzzy soft open set is called $\tau_{1} \tau_{2}$-fuzzy soft closed set.

The family of all $\tau_{1} \tau_{2^{-}}$fuzzy soft open (closed) sets in $\left(X, E, \tau_{1}, \tau_{2}\right)$ is denoted by $\tau_{1} \tau_{2} F S O\left(X, \tau_{1}, \tau_{2}\right)_{E}\left(\tau_{1} \tau_{2} F S C\left(X, \tau_{1}, \tau_{2}\right)_{E}\right)$, respectively.

Remark 2.17 [19] $\tau_{i}(i=1,2)$ - fuzzy soft open is $\tau_{1} \tau_{2}$-fuzzy soft open but the converse is not true.

Theorem 2.18 [19] If $\left(X, E, \tau_{1}, \tau_{2}\right)$ ) is a fuzzy soft bitopological space, then $\tau=\tau_{1} \tilde{\tau}_{2}$ isa fuzzy soft topological space over $(X, E)$.

Remark 2.19 [19] If $\left(X, E, \tau_{1}, \tau_{2}\right)$ is a fuzzy soft bitopological space, then $\tau=\tau_{1}{ }^{\tilde{1}} \tau_{2}$ is 
not a fuzzy soft topological space over $(X, E)$.

Definition 2.20 [19] Let $\left(X, E, \tau_{1}, \tau_{2}\right)$ be a fuzzy soft bitopological space and $f_{E} \tilde{\in}(\overline{X, E})$. Then the $\tau_{i}(i=1,2)$-fuzzy soft closure of $f_{E}$, denoted by $\tau_{i} l\left(f_{E}\right)$, is the intersection of all $\tau_{i}(i=1,2)$-fuzzy soft closed supersets of $f_{E}$.

Clearly, $\tau_{i} l\left(f_{E}\right)$ is the smallest $\tau_{i}(i=1,2)$ - fuzzy soft closed set over $(X, E)$ which con-tains $f_{E}$.

Definition 2.21 [19] Let $\left(X, E, \tau_{1}, \tau_{2}\right)$ be a fuzzy soft bitopological space and $f_{E} \tilde{\in}(\overline{X, E})$. Then the $\tau_{1} \tau_{2}$ - fuzzy soft closure of $f_{E}$, denoted by $\tau_{1} \tau_{2} c l\left(f_{E}\right)$, is the intersection of all $\tau_{1} \tau_{2}-$ fuzzy soft closed supersets of $f_{E}$.

Clearly, $\tau_{1} \tau_{2} c l\left(f_{E}\right)$ is the smallest $\tau_{1} \tau_{2}$ - fuzzy soft closed set over $(X, E)$ which contains $f_{E}$.

Remark 2.22 [19] If $\left(X, E, \tau_{1}, \tau_{2}\right)$ is a fuzzy soft bitopological space and $f_{E} \widetilde{\in}(\overline{X, E})$. Then $\tau_{1} \tau_{2} \operatorname{cl}\left(f_{E}\right) \widetilde{\subseteq} \tau_{i} c l\left(f_{E}\right)(i=1,2)$.

Definition 2.23 [19] Let $\left(X, E, \tau_{1}, \tau_{2}\right)$ be a fuzzy soft bitopological space and $f_{E} \tilde{\in}(\overline{X, E})$. Then the $\tau_{i}(i=1,2)$-fuzzy soft interior of $f_{E}$, denoted by $\tau_{i n t}\left(f_{E}\right)$, is the union of all $\tau_{i}(i$ $=1,2)$-fuzzy soft open subsets of $f_{E}$.

Clearly, $\tau_{i n t}\left(f_{E}\right)$ is the largest $\tau_{i}(i=1,2)$ - fuzzy soft open set over $(X, E)$ which contained in $f_{E}$. 
Definition 2.24 [19] Let $\left(X, E, \tau_{1}, \tau_{2}\right)$ be a fuzzy soft bitopological space and $f_{E} \tilde{\in}(\overline{X, E})$. Then the $\tau_{1} \tau_{2^{-}}$fuzzy soft interior of $f_{E}$, denoted by $\tau_{1} \tau_{2}$ int $\left(f_{E}\right)$, is the union of all $\tau_{1} \tau_{2^{-}}$ fuzzy soft open subsets of $f_{E}$.

Clearly, $\tau_{1} \tau_{2} c l\left(f_{E}\right)$ is the largest $\tau_{1} \tau_{2}$-fuzzy soft open set over $(X, E)$ which contained in $f_{E}$.

Remark 2.25 [19] If $\left(X, E, \tau_{1}, \tau_{2}\right)$ is a fuzzy soft bitopological space and $f_{E} \tilde{\in} \overline{(X, E)}$. Then $\operatorname{\tau int}_{i}\left(f_{E}\right)(i=1,2) \tilde{\subseteq} \tau_{1} \tau_{2} \operatorname{int}\left(f_{E}\right)$.

Definition 2.26 [27] Let $\left(X, E, \tau_{1}, \tau_{2}\right)$ be a soft bitopological space. Then, the family of all $\tau_{1} \tau_{2}$-fuzzy soft open sets is a supra fuzzy soft topology on $(X, E)$. This supra fuzzysoft topology, will denoted by $\tau_{12}$, i.e., $\tau_{12}=\tau_{1} \tau_{2} F S O\left(X, \tau_{1}, \tau_{2}\right)_{E}=\left\{g_{E}=g_{1_{E}} \tilde{\cup} g_{2_{E}}\right.$ : $\left.g_{i_{E}} \widetilde{\in} \tau_{i}, i=1,2\right\}$ and the triple $\left(X, E, \tau_{12}\right)$ is the supra fuzzy soft topological space associated to the fuzzy soft bitopological space $\left(X, E, \tau_{1}, \tau_{2}\right)$.

Definition 2.27 [25] A fuzzy soft set $f_{E}$ in a fuzzy soft bitopological space $\left(X, E, \tau_{1}, \tau_{2}\right)$ is called

(i) $(1,2)^{*}$-fuzzy soft pre open set if $f_{E} \widetilde{\subseteq} \tau_{1} \tau_{2}$ int $\left(\tau_{1} \tau_{2} c l\left(f_{E}\right)\right)$ and $(1,2)^{*}$-fuzzy soft pre closed set if $\tau_{1} \tau_{2} c l\left(\tau_{1} \tau_{2} \operatorname{int}\left(f_{E}\right)\right) \widetilde{\simeq} f_{E}$.

(ii) $(1,2)^{*}$-fuzzy soft semi open set if $f_{E} \widetilde{\subseteq} \tau_{1} \tau_{2} c l\left(\tau_{1} \tau_{2}\right.$ int $\left.\left(f_{E}\right)\right)$ and $(1,2)^{*}$-fuzzy soft semi closed set if $\tau_{1} \tau_{2}$ int $\left(\tau_{1} \tau_{2} c l\left(f_{E}\right)\right) \widetilde{\subseteq} f_{E}$.

(iii) $(1,2)^{*}$-fuzzy soft $\beta$-open set if $f_{E} \tilde{\subseteq} \tau_{1} \tau_{2} c l\left(\tau_{1} \tau_{2}\right.$ int $\left.\left(\tau_{1} \tau_{2} c l\left(f_{E}\right)\right)\right)$ and $(1,2)^{*}$-fuzzy soft $\beta$-closed set if $\tau_{1} \tau_{2}$ int $\left(\tau_{1} \tau_{2} c l\left(\tau_{1} \tau_{2} \operatorname{int}\left(f_{E}\right)\right)\right) \widetilde{\subseteq} f_{E}$.

Definition 2.28 [25] Let $\left(X, E, \tau_{1}, \tau_{2}\right)$ be a fuzzy soft bitopological space and $f_{E} \sim \overline{(X, E)}$. Then $f_{E}$ is called $(1,2)^{*}$-fuzzy soft b-open set (briefly, $(1,2)^{*}$-fsb-open) if $f_{E} \widetilde{\subseteq} \tau_{1} \tau_{2} \operatorname{int}\left(\tau_{1} \tau_{2} c l\left(f_{E}\right)\right) \tilde{U} \tau_{1} \tau_{2} c l\left(\tau_{1} \tau_{2} i n t\left(f_{E}\right)\right)$ 
Theorem 2.29 [25] Let $\left(X, E, \tau_{1}, \tau_{2}\right)$ be a fuzzy soft bitopological space. Then

(i) Every $(1,2)^{*}$-fuzzy soft pre open set is $(1,2)^{*}$-fuzzy soft b-open set.

(ii) Every $(1,2)^{*}$-fuzzy soft $b$-open set is $(1,2)^{*}$-fuzzy soft $\beta$-open set.

(iii) Every $(1,2)^{*}$-fuzzy soft semi open set is $(1,2)^{*}$-fuzzy soft b-open set.

Definition 2.30 [25] Let $\left(X, E, \tau_{1}, \tau_{2}\right)$ be a fuzzy soft bitopological space and $f_{E} \sim \overline{(X, E)}$. (i) $(1,2)^{*}$-fuzzy soft b-closure (briefly $\left.(1,2)^{*}-f \operatorname{sbcl}\left(f_{E}\right)\right)$ of a set $f_{E}$ in $\left(X, E, \tau_{1}, \tau_{2}\right)$ defined by $(1,2)^{*}-f \operatorname{sbcl}\left(f_{E}\right)=\sim \tilde{B}\left\{f_{E} \supseteq g_{E}\right.$ is a $(1,2)^{*}-f u z z y$ soft b-closed set in $\left(X, E, \tau_{1}, \tau_{2}\right)$. $\}$ (ii) $(1,2)^{*}$-fuzzy soft b-interior (briefly $\left.(1,2)^{*}-f \operatorname{sint}\left(f_{E}\right)\right)$ of a set $f_{E}$ in $\left(X, E, \tau_{1}, \tau_{2}\right)$ defined by $(1,2)^{*}-f \operatorname{sint}\left(f_{E}\right)=\tilde{}{ }^{2}\left\{\tilde{f} f_{E C} g_{E}\right.$ is a $(1,2)^{*}-f u z z y$ soft b-open set in $\left.\left(X, E, \tau_{1}, \tau_{2}\right).\right\}$ $(1,2)^{*}-f \operatorname{sbcl}\left(f_{E}\right)$ is the smallest $(1,2)^{*}$-fuzzy soft b-closed set in $\left(X, E, \tau_{1}, \tau_{2}\right)$ which contains $f_{E}$ and $(1,2)^{*}-f \operatorname{sbcl}\left(f_{E}\right)$ is the largest $(1,2)^{*}$-fuzzy soft $b$-closed set in $\left(X, E, \tau_{1}, \tau_{2}\right)$ which is contained in $f_{E}$.

Definition 2.31 [3] Let $(\overline{X, E})$ and $(\widetilde{Y, K})$ be the families of all fuzzy soft sets over $X$ and $Y$ , respectively. Let $\phi: X \rightarrow Y$ and $\psi: E \rightarrow K$ be two functions. Then the pair $(\phi, \psi)$ is called a fuzzy soft mapping from $X$ to $Y$, and denoted by $(\phi, \psi): \overline{(X, E)} \rightarrow \overline{(Y, K})$.

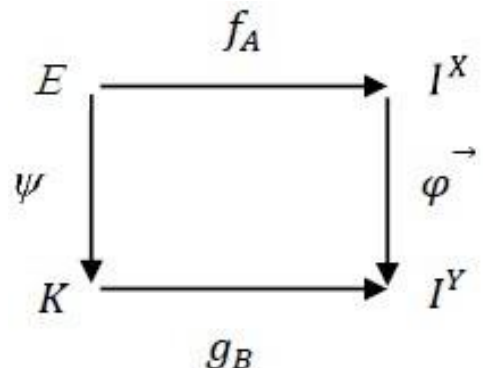

In the diagram, $f_{A} \widetilde{\in}(\overline{X, E}), g_{B} \widetilde{\in}(\overline{Y, K})$ and Let $\phi: I^{X} \rightarrow I^{Y}$ is the forward powerset operator (see e.g. [23]), that is $\phi^{\rightarrow}(h):=\phi(h)$ for all $h \in I^{X}$. Since componentwise composition of two fuzzy soft functions $(\phi, \psi)$ from $(\overline{X, E})$ to $(\overline{Y, K})$ and $(\phi, \bar{\psi})$ from $(\overline{Y, K})$ to $\overline{\ell, T}$ ) is obviously a fuzzy soft function $(\phi \circ \phi, \bar{\psi} \circ \psi)$ from $(\overline{X, E})$ to $\overline{Z, T})$, where $\psi$ $: E \rightarrow K$ and $\bar{\psi}: K \rightarrow T$ and $\phi: I^{X} \rightarrow I^{Y}$ and $\phi: I^{Y} \rightarrow I^{Z}$ and the pair of identities $\left(i d x, i d_{E}\right)$ from $(\overline{X, E})$ to $(\overline{X, E})$ is the identical morphism.

(1) Let $f_{A} \widetilde{\in}(\overline{X, E})$. Then the image of $f_{A}$ under the fuzzy soft mapping $(\phi, \psi)$ is the fuzzy soft set over $Y$ defiped by $(\phi, \psi)\left(f_{A}\right)$, where $\forall k \in \psi(E), \forall y \in Y$,

$\phi\left(f_{A}\right)(k)(y)=\begin{array}{ll}\phi(x)=y & \psi(e) f_{A}(e)(x), \\ \tilde{0}_{E}, & \text { if } x \in \phi^{-1}(y) ; \\ \text { otherwise. }\end{array}$

(2) Let $g_{B} \widetilde{\in}(\overline{Y, K})$. Then the inverse image of $f_{B}$ under the fuzzy soft mapping $(\phi, \psi)$ is the fuzzy soft set over $X$ defined by $(\phi, \psi)^{-1}\left(g_{B}\right)$, where $\forall e \in \psi^{-1}(K), \forall x \in X, \phi^{-1}\left(g_{B}\right)(e)(x)=$ $g_{B}(\psi(e))(\phi(x))$. If both $\phi$ and $\psi$ is injective then the fuzzy soft mapping $(\phi, \psi)$ is said to be injective. If both $\phi$ and $\psi$ is surjective then the fuzzy soft mapping $(\phi, \psi)$ is said to be surjective. $(\phi, \psi)$ is said to be bijective if it is both injective and surjective. 


\section{$3(1,2)^{*}$-fuzzy soft $b$-continuous maps}

In this section we introduce the concept of $(1,2)^{*}$-fuzzy soft $b$-continuous functions and some of their properties are discussed.

We begin by the following concepts which will be used in the sequel.

Definition 3.1 A fuzzy soft mapping $(\phi, \psi):\left(X, E, \tau_{1}, \tau_{2}\right) \rightarrow\left(Y, K, \sigma_{1}, \sigma_{2}\right)$ is said to be (i) $(1,2)^{*}$-fuzzy soft-continuous (briefly $(1,2)^{*}$-fs-continuous) if the inverse image of every $\sigma_{1} \sigma_{2}$-fuzzy soft open set in $\left(Y, K, \sigma_{1}, \sigma_{2}\right)$ is a $\tau_{1} \tau_{2}$-fuzzy soft open set in $\left(X, E, \tau_{1}, \tau_{2}\right)$.

(ii) $(1,2)^{*}$-fuzzy soft semi-continuous (briefly $(1,2)^{*}$-fss-continuous) the inverse image of every $\sigma_{1} \sigma_{2}$-fuzzy soft open set in $\left(Y, K, \sigma_{1}, \sigma_{2}\right)$ is $(1,2)^{*}$-fuzzy soft semi open set in $\left(X, E, \tau_{1}, \tau_{2}\right)$.

(iii) $(1,2)^{*}$-fuzzy soft pre-continuous (briefly $(1,2)^{*}-f s p$-continuous) the inverse image of every $\sigma_{1} \sigma_{2}$-fuzzy soft open set in $\left(Y, K, \sigma_{1}, \sigma_{2}\right)$ is a $(1,2)^{*}$-fuzzy soft pre open set in $\left(X, E, \tau_{1}, \tau_{2}\right)$.

(iv) $(1,2)^{*}$-fuzzy soft $\beta$-continuous (briefly $(1,2)^{*}-f s \beta$-continuous) the inverse image of ev-ery $\sigma_{1} \sigma_{2}$-fuzzy soft open set in $\left(Y, K, \sigma_{1}, \sigma_{2}\right)$ is a $(1,2)^{*}$-fuzzy soft $\beta$-open set in $\left(X, E, \tau_{1}, \tau_{2}\right)$.

Definition 3.2 A fuzzy soft mapping $(\phi, \psi):\left(X, E, \tau_{1}, \tau_{2}\right) \rightarrow\left(Y, K, \sigma_{1}, \sigma_{2}\right)$ is said to be $(1,2)^{*}$-fuzzy soft b-continuous (briefly $(1,2)^{*}$-fsb-continuous) the inverse image of every $\sigma_{1} \sigma_{2}$ fuzzy soft open set in $\left(Y, K, \sigma_{1}, \sigma_{2}\right)$ is a $(1,2)^{*}$-fuzzy soft b-open set in $\left(X, E, \tau_{1}, \tau_{2}\right)$.

Example 3.3 Let $X=Y=\{x, y\}, E=K=\left\{e_{1}, e_{2}\right\}$. Let $\tau_{1}=\left\{\widetilde{0}_{E}, \widetilde{1}_{E}, f_{1_{E}}\right\}, \tau_{2}=$ $\left\{\widetilde{0}_{E}, \tilde{1}_{E}, f_{2_{E}}\right\}$, where $f_{1_{E}}=\left\{f_{1}\left(e_{1}\right)=\{x / 0.5, y / 0.0\}, f_{1}\left(e_{2}\right)=\{x / 0.0, y / 0.0\}=\widetilde{0}\right\}$,

$f_{2_{E}}=\left\{f_{2}\left(e_{1}\right)=\{x / 0.0, y / 0.7\}, f_{2}\left(e_{2}\right)=\{x / 0.0, y / 0.0\}=\widetilde{0}\right\}$.

It is clear that $\left(X, E, \tau_{1}, \tau_{2}\right)$ is a fuzzy soft bitopological space.

The $\tau_{1} \tau_{2}$-fuzzy soft open sets are $\left\{\tilde{0}_{E}, \tilde{1}_{E}, f_{1_{E}}, f_{2_{E}}, f_{3_{E}}\right\}$, where

$f_{3_{E}}=\boldsymbol{f}_{\mathbf{1}_{E}} \tilde{\cup} \boldsymbol{f}_{2_{E}}=\left\{\boldsymbol{f}_{3}\left(e_{1}\right)=\{x / 0.5, y / 0.7\}, f_{3}\left(e_{2}\right)=\{x / 0.0, y / 0.0\}=\widetilde{0}\right\}$, and $(1,2)^{*}$-fuzzy soft b-open sets are $\left\{\tilde{0}_{E}, \tilde{1}_{E}, f_{1_{E}}, f_{2_{E}}, f_{3 E}, f_{4_{E}}, f_{5_{E}}, f_{6_{E}}, f_{7_{E}}, f_{8_{E}}, f_{9_{E}}, f_{10_{E}}, f_{11_{E}}\right\}$, where $f_{1_{E}}, f_{2_{E}}, f_{3_{E}}$ are shown as above and

$f_{4 E}=\left\{f_{4}\left(e_{1}\right)=\{x / 0.5, y / 0.0\}, f_{4}\left(e_{2}\right)=\{x / 0.3, y / 0.0\}\right\}$,

$f_{5_{E}}=\left\{f_{5}\left(e_{1}\right)=\{x / 0.5, y / 0.0\}, f_{5}\left(e_{2}\right)=\{x / 0.0, y / 0.6\}\right\}$,

$f_{6_{E}}=\left\{f_{6}\left(e_{1}\right)=\{x / 0.5, y / 0.0\}, f_{6}\left(e_{2}\right)=\{x / 0.3, y / 0.6\}\right\}$,

$f_{7_{E}}=\left\{f_{7}\left(e_{1}\right)=\{x / 0.0, y / 0.7\}, f_{7}\left(e_{2}\right)=\{x / 0.3, y / 0.0\}\right\}$,

$f_{8_{E}}=\left\{f_{8}\left(e_{1}\right)=\{x / 0.0, y / 0.7\}, f_{8}\left(e_{2}\right)=\{x / 0.3, y / 0.6\}\right\}$,

$f_{9_{E}}=\left\{f_{9}\left(e_{1}\right)=\{x / 0.0, y / 0.7\}, f_{9}\left(e_{2}\right)=\{x / 0.0, y / 0.6\}\right\}$,

$f_{10_{E}}=\left\{f_{10}\left(e_{1}\right)=\{x / 0.5, y / 0.7\}, f_{10}\left(e_{2}\right)=\{x / 0.3, y / 0.0\}\right\}$,

$f_{11_{E}}=\left\{f_{11}\left(e_{1}\right)=\{x / 0.5, y / 0.7\}, f_{11}\left(e_{2}\right)=\{x / 0.0, y / 0.6\}\right\}$.

Let $\sigma_{1}=\left\{0_{K}, 1_{K}, g_{1_{K}}, g_{2_{K}}\right\}, \sigma_{2}=\left\{\widetilde{0}_{K}, \widetilde{1}_{K}, g_{3 K}\right\}$, where

$g_{1_{K}}=\left\{g_{1}\left(e_{1}\right)=\{x / 0.5, y / 0.0\}, g_{1}\left(e_{2}\right)=\{x / 0.0, y / 0.0\}=\widetilde{0}\right\}$,

$g_{2_{K}}=\left\{g_{2}\left(e_{1}\right)=\{x / 0.5, y / 0.0\}, g_{2}\left(e_{2}\right)=\{x / 0.3, y / 0.0\}\right\}$,

$g_{3_{K}}=\left\{g_{3}\left(e_{1}\right)=\{x / 0.5, y / 0.7\}, g_{3}\left(e_{2}\right)=\{x / 0.0, y / 0.0\}=\tilde{0}\right\}$.

It is clear that $\left(X, E, \tau_{1}, \tau_{2}\right)$ is a fuzzy soft bitopological space.

The $\sigma_{1} \sigma_{2}$-fuzzy soft open sets are $\left\{\widetilde{0}_{K}, \tilde{1}_{K}, g_{1_{K}}, g_{2_{K}}, g_{3_{K}}, g_{4_{K}}\right\}$, where 
$g_{2_{K}}=g_{1_{E}} \tilde{\cup} g_{2_{E}}, g_{3 K}=g_{1_{E}} \tilde{\cup} g_{3 E}$,

$g_{4 K}=g_{2_{E}} \tilde{U} g_{3_{E}}=\left\{g_{4}\left(e_{1}\right)=\{x / 0.5, y / 0.7\}, g_{4}\left(e_{2}\right)=\{x / 0.3, y / 0.0\}\right\}$.

It is clear that $\left(Y, K, \sigma_{1}, \sigma_{2}\right)$ is a fuzzy soft bitopological space.

Now define $\phi:\left(X, \tau_{1}, \tau_{2}\right) \rightarrow\left(Y, \sigma_{1}, \sigma_{2}\right)$ and $\psi: E \rightarrow K$ such that

$\phi\left(x, \mu_{f\left(e_{i}\right)}(x)\right)=\left(x, \mu_{g\left(e_{i}\right)}(x)\right), \psi\left(e_{i}\right)=e_{i}, i=1,2$.

Then the inverse image of every $\sigma_{1} \sigma_{2}$-fuzzy soft open sets are $\tau_{1} \tau_{2}$-fuzzy $b$-soft open sets are $(1,2)^{*}$-fuzzy soft b-open sets in $\left(X, E, \tau_{1}, \tau_{2}\right)$. Thus $(\phi, \psi):\left(X, E, \tau_{1}, \tau_{2}\right) \rightarrow\left(Y, K, \sigma_{1}, \sigma_{2}\right)$ is $(1,2)^{*}$-fuzzy soft b-continuous.

Theorem 3.4 Every $(1,2)^{*}$-fuzzy soft continuous map is $(1,2)^{*}$-fuzzy soft b-continuous.

Proof. Let $(\phi, \psi):\left(X, E, \tau_{1}, \tau_{2}\right) \quad\left(Y, K, \sigma_{1}, \sigma_{2}\right)$ be a $(1,2)^{*}$-fuzzy soft $b$-continuous map. Let $f_{A}$ be $\sigma_{1} \sigma_{2}$-fuzzy soft open set in $\left(Y, K, \sigma_{1}, \sigma_{2}\right)$. Since $(\phi, \psi)$ is a $(1,2)^{*}$-fuzzy soft $b$ continuous map, $(\phi, \psi)^{-1}\left(f_{E}\right)$ is $\tau_{1} \tau_{2}$-fuzzy soft open set in $\left(X, E, \tau_{1}, \tau_{2}\right)$. And $\operatorname{so}(\phi$, $\psi)^{-1}\left(f_{E}\right)$ is $(1,2)^{*}$-fuzzy soft $b$-open set in $\left(X, E, \tau_{1}, \tau_{2}\right)$. Therefore $(\phi, \psi)$ is a $(1,2)^{*}$ - fuzzy soft $b$-continuous map.

The converse of the above theorem is not true as shown in the following example.

Example 3.5 Consider the Example 3.3, $(\phi, \psi):\left(X, E, \tau_{1}, \tau_{2}\right) \quad\left(Y, K, \sigma_{1}, \sigma_{2}\right)$ is $(1,2)^{*}$ - fuzzy soft $b$-continuous but not $(1,2)^{*}$-fuzzy soft continuous.

Theorem 3.6 Let $(\phi, \psi):\left(X, E, \tau_{1}, \tau_{2}\right) \rightarrow\left(Y, K, \sigma_{1}, \sigma_{2}\right)$ be a fuzzy soft mapping. Then the following statements are equivalent:

(i) $(\phi, \psi)$ is $(1,2)^{*}$-fuzzy soft b-continuous.

(ii) The inverse image of each $\sigma_{1} \sigma_{2}$-fuzzy soft closed set in $\left(Y, K, \sigma_{1}, \sigma_{2}\right)$ is a $(1,2)^{*}$-fuzzy soft $b$-closed set in $\left(X, E, \tau_{1}, \tau_{2}\right)$.

Proof. $(i) \Rightarrow(i i)$ : Let $g_{K}$ be a $\sigma_{1} \sigma_{2}$-fuzzy soft closed set in $\left(Y, K, \sigma_{1}, \sigma_{2}\right)$. Then $g_{K}^{c}$ is a $\sigma_{1} \sigma_{2}$-fuzzy soft open set in $\left(Y, K, \sigma_{1}, \sigma_{2}\right)$. Thus $(\phi, \psi)^{-1}\left(g^{c} k^{\text {is a }}(1,2)^{*}\right.$-fuzzy soft $b$-open set in $\left(X, E, \tau_{1}, \tau_{2}\right)$ and $(\phi, \psi)^{-1}\left(g_{K}^{c}\right)=\left[(\phi, \psi)^{-1}\left(g_{K}\right)\right]^{c}$. Hence $(\phi, \psi)^{-1}\left(g_{K}\right.$ is a $(1,2)^{*}$-fuzzy soft $b$-closed set in $\left(X, E, \tau_{1}, \tau_{2}\right)$.

$(i i) \Rightarrow(i)$ : Let $g_{K}$ be a $\sigma_{1} \sigma_{2}$-fuzzy soft set in $\left(Y, K, \sigma_{1}, \sigma_{2}\right)$. Then $g^{c}{ }_{K}$ is a $\sigma_{1} \sigma_{2}$-fuzzy soft closed set and by $(i i)$, we have $(\phi, \psi)^{-1}\left(g_{K}^{c}\right)$ is $(1,2)^{*}$-fuzzy soft $b$-closed set in $\left(X, E, \tau_{1}, \tau_{2}\right)$ and $(\phi, \psi)^{-1}\left(g_{K}^{c}\right)=\left[(\phi, \psi)^{-1}\left(g_{K}\right)\right]^{c}$. Hence $(\phi, \psi)^{-1}\left(g_{K}\right)$ is a $(1,2)^{*}$-fuzzy soft $b$-open set in $\left(X, E, \tau_{1}, \tau_{2}\right)$. Therefore $(\phi, \psi)$ is a $(1,2)^{*}$-fuzzy soft $b$-continuous map.

Theorem 3.7 Let $(\phi, \psi):\left(X, E, \tau_{1}, \tau_{2}\right) \quad\left(Y, K, \sigma_{1}, \sigma_{2}\right)$ be a fuzzy soft map. Then (i) Every $(1,2)^{*}$-fuzzy soft semi continuous map is $(1,2)^{*}$-fuzzy soft b-continuous.

(ii) Every $(1,2)^{*}$-fuzzy soft pre continuous map is $(1,2)^{*}$-fuzzy soft $b$-continuous.

(iii) Every $(1,2)^{*}$-fuzzy soft b-continuous map is $(1,2)^{*}$-fuzzy soft $\beta$-continuous.

Proof. (i) Assume that $(\phi, \psi)$ is $(1,2)^{*}$-fuzzy semi continuous and $g_{K}$ be a $\sigma_{1} \sigma_{2}$-fuzzysoft in $\left(Y, K, \sigma_{1}, \sigma_{2}\right)$. Then $(\phi, \psi)^{-1}\left(g_{K}\right)$ is a $(1,2)^{*}$-fuzzy semi open set in $\left(X, E, \tau_{1}, \tau_{2}\right)$. Since every $(1,2)^{*}$-fuzzy semi open set is $(1,2)^{*}$-fuzzy $b$-open set and hence $(\phi, \psi)^{-1}\left(g_{K}\right)$ is a $(1$, $2)^{*}$-fuzzy soft $b$-open set in $\left(X, E, \tau_{1}, \tau_{2}\right)$. Therefore $(\phi, \psi)$ is a $(1,2)^{*}$-fuzzy soft $b$-continuous map.

The proof of (ii) and (iii) are similar to $(i)$. 


\section{Korean Nathematical Society}

ISSN 1015-8634 (Print) ISSN22343016/Online)

Remark 3.8 The converse of the above implications need not be true as shown in the following examples.

Example 3.9 Let $X=Y=\{x, y\}, E=K=\left\{e_{1}, e_{2}\right\}$. Let $\tau_{1}=\left\{\widetilde{0}_{E}, \tilde{1}_{E}, f_{1_{E}}\right\}, \tau_{2}=$ $\left\{\widetilde{0}_{E}, \widetilde{1}_{E}, f_{2_{E}}\right\}$, where $f_{1_{E}}=\left\{f_{1}\left(e_{1}\right)=\{x / 0.0, y / 0.7\}, f_{1}\left(e_{2}\right)=\{x / 0.0, y / 0.0\}=\widetilde{0}\right\}$,

$f_{2_{E}}=\left\{f_{2}\left(e_{1}\right)=\{x / 0.0, y / 0.7\}, f_{2}\left(e_{2}\right)=\{x / 0.3, y / 0.7\}\right\}$,

It is clear that $\left(X, E, \tau_{1}, \tau_{2}\right)$ is a fuzzy soft bitopological space.

The $\tau_{1} \tau_{2}$-fuzzy soft open sets are $\left\{\widetilde{0}_{E}, \widetilde{1}_{E}, f_{1_{E}}, f_{2_{E}}\right\}$ and $(1,2)^{*}$-fuzzy soft b-open sets are are all fuzzy soft subsets in $(X, E)$ i.e.

$\left\{\widetilde{0}_{E}, \tilde{1}_{E}, f_{1_{E}}, f_{2_{E}}, f_{3_{E}}, f_{4_{E}}, f_{5_{E}}, f_{6_{E}}, f_{7_{E}}, f_{8_{E}}, f_{9_{E}}, f_{10_{E}}, f_{11_{E}}, f_{12_{E}}, f_{13_{E}}, f_{14_{E}}\right\}$ where $f_{1_{E}}, f_{2_{E}}$ are shown as above and

$f_{3_{E}}=\left\{f_{4}\left(e_{1}\right)=\{x / 0.5, y / 0.0\}, f_{4}\left(e_{2}\right)=\{x / 0.0, y / 0.0\}=\widetilde{0}\right\}$,

$f_{4 E}=\left\{f_{4}\left(e_{1}\right)=\{x / 0.5, y / 0.7\}, f_{4}\left(e_{2}\right)=\{x / 0.0, y / 0.0\}=\widetilde{0}\right\}$,

$f_{5 E}=\left\{f_{5}\left(e_{1}\right)=\{x / 0.0, y / 0.0\}=\widetilde{0}, f_{5}\left(e_{2}\right)=\{x / 0.3, y / 0.0\}\right\}$,

$f_{6_{E}}=\left\{f_{6}\left(e_{1}\right)=\{x / 0.0, y / 0.0\}=\widetilde{0}, f_{6}\left(e_{2}\right)=\{x / 0.0, y / 0.6\}\right\}$,

$f_{7_{E}}=\left\{f_{7}\left(e_{1}\right)=\{x / 0.0, y / 0.0\}=\widetilde{0}, f_{7}\left(e_{2}\right)=\{x / 0.3, y / 0.6\}\right\}$,

$f_{8_{E}}=\left\{f_{8}\left(e_{1}\right)=\{x / 0.5, y / 0.0\}, f_{8}\left(e_{2}\right)=\{x / 0.3, y / 0.0\}\right\}$,

$f_{9_{E}}=\left\{f_{9}\left(e_{1}\right)=\{x / 0.5, y / 0.0\}, f_{9}\left(e_{2}\right)=\{x / 0.0, y / 0.6\}\right\}$,

$f_{1 \mathrm{O}_{E}}=\left\{f_{1 \mathrm{O}}\left(e_{1}\right)=\{x / 0.5, y / 0.0\}, f_{10}\left(e_{2}\right)=\{x / 0.3, y / 0.6\}\right\}$,

$f_{11_{E}}=\left\{f_{11}\left(e_{1}\right)=\{x / 0.0, y / 0.7\}, f_{11}\left(e_{2}\right)=\{x / 0.3, y / 0.0\}\right\}$.

$f_{12_{E}}=\left\{f_{9}\left(e_{1}\right)=\{x / 0.0, y / 0.7\}, f_{9}\left(e_{2}\right)=\{x / 0.0, y / 0.6\}\right\}$,

$f_{13_{E}}=\left\{f_{10}\left(e_{1}\right)=\{x / 0.5, y / 0.7\}, f_{10}\left(e_{2}\right)=\{x / 0.3, y / 0.0\}\right\}$,

$f_{14 E}=\left\{f_{11}\left(e_{1}\right)=\{x / 0.5, y / 0.7\}, f_{11}\left(e_{2}\right)=\{x / 0.0, y / 0.6\}\right\}$.

and $(1,2)^{*}$-fuzzy soft semi open sets are $\left\{\widetilde{0}_{E}, \tilde{1}_{E}, f_{\mathbf{1}_{E}}, f_{2_{E}}\right\}$

Let $\sigma_{1}=\left\{0_{K}, \widetilde{1}_{K}, g_{1_{K}}\right\}, \sigma_{2}=\left\{\widetilde{0}_{K}, \widetilde{1}_{K}, g_{2_{K}}\right\}$, where

$g_{1_{K}}=\left\{g_{1}\left(e_{1}\right)=\{x / 0.0, y / 0.7\}, g_{1}\left(e_{2}\right)=\{x / 0.0, y / 0.0\}=\widetilde{0}\right\}$,

$g_{2_{K}}=\left\{g_{2}\left(e_{1}\right)=\{x / 0.0, y / 0.7\}, g_{2}\left(e_{2}\right)=\{x / 0.3, y / 0.6\}\right\}$.

It is clear that $\left(X, E, \tau_{1}, \tau_{2}\right)$ is a fuzzy soft bitopological space.

The $\sigma_{1} \sigma_{2}$-fuzzy soft open sets are $\left\{\widetilde{0}_{K}, \widetilde{1}_{K}, g_{1_{K}}, g_{2_{K}}, g_{3_{K}}\right\}$, where

$g_{3 K}=g_{1_{E}} \widetilde{\cup} g_{2_{E}}=\left\{g_{3}\left(e_{1}\right)=\{x / 0.5, y / 0.7\}, g_{3}\left(e_{2}\right)=\{x / 0.3, y / 0.0\}\right\}$.

It is clear that $\left(Y, K, \sigma_{1}, \sigma_{2}\right)$ is a fuzzy soft bitopological space.

Now define $\phi:\left(X, \tau_{1}, \tau_{2}\right) \rightarrow\left(Y, \sigma_{1}, \sigma_{2}\right)$ and $\psi: E \rightarrow K$ such that

$\phi\left(x, \mu_{f\left(e_{i}\right)}(x)\right)=\left(x, \mu_{g\left(e_{i}\right)}(x)\right), \psi\left(e_{i}\right)=e_{i}, i=1,2$. Then

$(\phi, \psi):\left(X, E, \tau_{1}, \tau_{2}\right) \rightarrow\left(Y, K, \sigma_{1}, \sigma_{2}\right)$ is $(1,2)^{*}$-fuzzy soft b-continuous. But the inverse image of $\sigma_{1} \sigma_{2}$-fuzzy soft open sets is not a $(1,2)^{*}$-fuzzy soft semi open sets in $\left(X, E, \tau_{1}, \tau_{2}\right)$.

Since $(\phi, \psi)^{-1}\left(g_{1_{K}}\right)=f_{1_{E}}$ which is not $(1,2)^{*}$-fuzzy soft semi open sets in $\left(X, E, \tau_{1}, \tau_{2}\right)$. 
Therefore $(\phi, \psi):\left(X, E, \tau_{1}, \tau_{2}\right) \rightarrow\left(Y, K, \sigma_{1}, \sigma_{2}\right)$ is not $(1,2)^{*}$-fuzzy soft semi continuous.

Example 3.10 Consider the Example 3.2, $(\phi, \psi):\left(X, E, \tau_{1}, \tau_{2}\right) \rightarrow \quad\left(Y, K, \sigma_{1}, \sigma_{2}\right)$ is $(1,2)^{*}$-fuzzy soft b-continuous but not $(1,2)^{*}$-fuzzy soft pre continuous. Since the $(1,2)^{*}-$ fuzzy soft pre open set in $\left(X, E, \tau_{1}, \tau_{2}\right)$ are $\left\{\widetilde{0}_{E}, \widetilde{1}_{E}, f_{1_{E}}, f_{2_{E}}, f_{3 E}, f_{10_{E}}, f_{11_{E}}\right\}$ and $(\phi, \psi)^{-1}\left(g_{2}\right)_{K}=f_{4}$, which is not $(1,2)^{*}$-fuzzy soft pre open set in $\left(X, E, \tau_{1}, \tau_{2}\right)$.

Example 3.11 Let $X=Y=\{x, y\}, E=K=\left\{e_{1}, e_{2}\right\}$.

Let $\tau_{1}=\left\{\widetilde{0}_{E}, \widetilde{1}_{E}, f_{1_{E}}\right\}, \tau_{2}=\left\{\widetilde{0}_{E}, \widetilde{1}_{E}, f_{2_{E}}\right\}$, where

$f_{1_{E}}=\left\{f_{1}\left(e_{1}\right)=\{x / 0.5, y / 0.0\}, f_{1}\left(e_{2}\right)=\{x / 0.0, y / 0.0\}=\widetilde{0}\right\}$,

$f_{2_{E}}=\left\{f_{2}\left(e_{1}\right)=\{x / 0.0, y / 0.7\}, f_{2}\left(e_{2}\right)=\{x / 0.0, y / 0.0\}=\widetilde{0}\right\}$,

It is clear that $\left(X, E, \tau_{1}, \tau_{2}\right)$ is a fuzzy soft bitopological space.

The $\tau_{1} \tau_{2}$-fuzzy soft open sets are $\left\{\tilde{0}_{E}, \tilde{1}_{E}, \boldsymbol{f}_{1_{E}}, \boldsymbol{f}_{2_{E}}, \boldsymbol{f}_{3 E}\right\}$ where

$f_{3_{E}}=f_{1_{E}} \tilde{\cup} f_{2_{E}}=\left\{f_{3}\left(e_{1}\right)=\{x \wedge 0.5, y / 0.7\}, f_{3}\left(e_{2}\right)=\{x / 0.0, y \wedge .0\}=\widetilde{0}\right\}$, and $(1,2)^{*}$-fuzzy soft b-open sets are $\left\{\tilde{0}_{E}, \tilde{1}_{E}, \boldsymbol{f}_{\mathbf{1}_{E}}, \boldsymbol{f}_{2_{E}}, \boldsymbol{f}_{3_{E}}, \boldsymbol{f}_{4_{E}}, \boldsymbol{f}_{5_{E}}, \boldsymbol{f}_{6_{E}}, \boldsymbol{f}_{7_{E}}, \boldsymbol{f}_{8_{E}}, \boldsymbol{f}_{9_{E}}, \boldsymbol{f}_{10_{E}}, \boldsymbol{f}_{11_{E}}\right\}$, where $f_{1 E}, f_{2 E}, f_{3 E}$ are shown as above and

$f_{4_{E}}=\left\{f_{4}\left(e_{1}\right)=\{x / 0.5, y / 0.0\}, f_{4}\left(e_{2}\right)=\{x / 0.3, y / 0.0\}\right\}$,

$f_{5_{E}}=\left\{f_{5}\left(e_{1}\right)=\{x / 0.5, y / 0.0\}, f_{5}\left(e_{2}\right)=\{x / 0.0, y / 0.6\}\right\}$,

$f_{6_{E}}=\left\{f_{6}\left(e_{1}\right)=\{x / 0.5, y / 0.0\}, f_{6}\left(e_{2}\right)=\{x / 0.3, y / 0.6\}\right\}$,

$f_{7_{E}}=\left\{f_{7}\left(e_{1}\right)=\{x / 0.5, y / 0.0\}, f_{7}\left(e_{2}\right)=\{x / 0.3, y / 0.6\}\right\}$,

$f_{8_{E}}=\left\{f_{8}\left(e_{1}\right)=\{x / 0.0, y / 0.7\}, f_{8}\left(e_{2}\right)=\{x / 0.0, y / 0.6\}\right\}$,

$f_{9_{E}}=\left\{f_{9}\left(e_{1}\right)=\{x / 0.0, y / 0.7\}, f_{9}\left(e_{2}\right)=\{x / 0.3, y / 0.6\}\right\}$,

$f_{1 \mathrm{O}_{E}}=\left\{f_{1 \mathrm{O}}\left(e_{1}\right)=\{x / 0.5, y / 0.7\}, f_{10}\left(e_{2}\right)=\{x / 0.3, y / 0.0\}\right\}$,

$f_{11_{E}}=\left\{f_{11}\left(e_{1}\right)=\{x / 0.5, y / 0.7\}, f_{11}\left(e_{2}\right)=\{x / 0.0, y / 0.6\}\right\}$. and $(1,2)^{*}$-fuzzy soft $\beta$-open sets are $\left.\tilde{\{} 0_{E}, 11_{E}, f_{1_{E}}, f_{2_{E}}, f_{3_{E}}, f_{4_{E}}, f_{5_{E}}, f_{6_{E}}, f_{7 E}, f_{8_{E}}, f_{9_{E}}, f_{10_{E}}, f_{11_{E}}, f_{12_{E}}, f_{13_{E}}\right\}$,

where $f_{i_{E}} ; i=1,2, \ldots, 11$ are shown as above and $f_{12_{E}}=\left\{f_{12}\left(e_{1}\right)=\{x / 0.5, y / 0.0\}, f_{12}\left(e_{2}\right)=\right.$ $\{x / 0.0, y / 0.0\}=0\}, f_{13 E}=\left\{f_{13}\left(e_{1}\right)=\{x / 0.0, y \wedge .0\}=\widetilde{0}, f_{13}\left(e_{2}\right)=\{x / 0.0, y \wedge .6\}\right\}$,

Let $\sigma_{1}=\left\{0_{K}, \tilde{1}_{K}, g_{1_{K}}, g_{2_{K}}, g_{3 K}\right\}, \sigma_{2}=\left\{\widetilde{0}_{K}, \tilde{1}_{K}, g_{4_{K}}, g_{5 K}\right\}$, where

$g_{1_{K}}=\left\{g_{1}\left(e_{1}\right)=\{x / 0.5, y / 0.0\}, g_{1}\left(e_{2}\right)=\{x / 0.0, y / 0.0\}=\widetilde{0}\right\}$,

$g_{2_{K}}=\left\{g_{2}\left(e_{1}\right)=\{x / 0.5, y / 0.0\}, g_{2}\left(e_{2}\right)=\{x / 0.3, y / 0.0\}\right\}$,

$g_{3_{K}}=\left\{g_{3}\left(e_{1}\right)=\{x / 0.5, y / 0.7\}, g_{3}\left(e_{2}\right)=\{x / 0.3, y / 0.0\}\right\}$

$g_{4_{K}}=\left\{g_{4}\left(e_{1}\right)=\{x / 0.0, y / 0.0\}=\tilde{0}, g_{4}\left(e_{2}\right)=\{x / 0.3, y / 0.0\}\right\}$,

$g_{5_{K}}=\left\{g_{5}\left(e_{1}\right)=\{x / 0.0, y / 0.7\}, g_{3}\left(e_{5}\right)=\{x / 0.3, y / 0.0\}=0\right\}$,

It is clear that $\left(Y, K, \sigma_{1}, \sigma_{2}\right)$ is a fuzzy soft bitopological space. The $\sigma_{1} \sigma_{2}$ fuzzy soft open sets are $\left\{\tilde{0}_{K}, \tilde{1}_{K}, g_{1_{K}}, g_{2_{K}}, g_{3 K}, g_{4_{K}}, g_{5_{K}}\right\}$

Now define $\phi:\left(X, \tau_{1}, \tau_{2}\right) \rightarrow\left(Y, \sigma_{1}, \sigma_{2}\right)$ and $\psi: E \rightarrow K$ such that $\phi\left(x, \mu f\left(e_{i}\right)(x)\right)=$ $\left(x, \mu_{g\left(e_{i}\right)}(x)\right), \psi\left(e_{i}\right)=e_{i}, i=1,2$. Then $(\phi, \psi):\left(X, E, \tau_{1}, \tau_{2}\right) \rightarrow\left(Y, K, \sigma_{1}, \sigma_{2}\right)$ is $(1,2)^{*}-$ fuzzy soft $\beta$-continuous but not $(1,2)^{*}$-fuzzy soft b-continuous, since $(\phi, \psi)^{-1}\left(g_{5 K}\right)$ is not $(1,2)^{*}$-fuzzy soft b-open set in $\left(X, E, \tau_{1}, \tau_{2}\right)$.

Remark 3.12 The above discussions are summarized in the following diagram: 


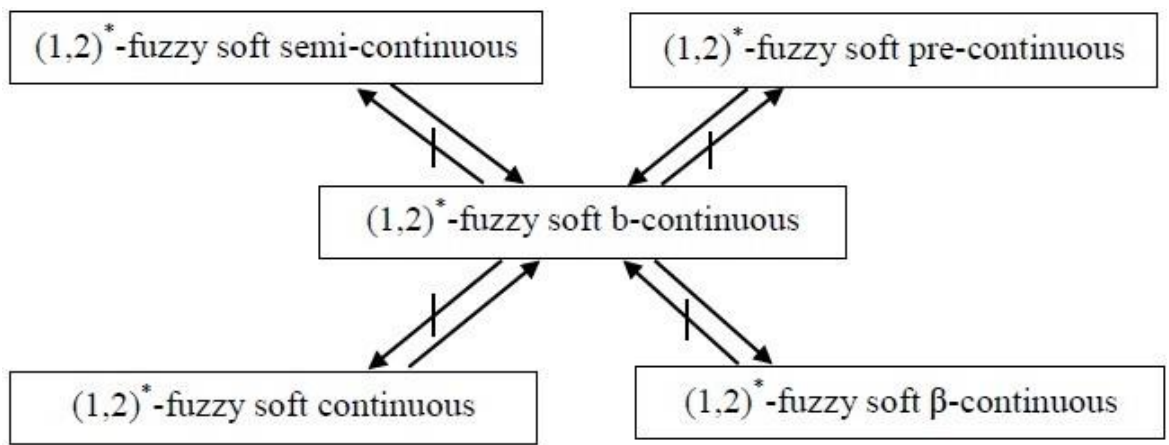


Theorem 3.13 Let $(\phi, \psi):\left(X, E, \tau_{1}, \tau_{2}\right) \rightarrow\left(Y, K, \sigma_{1}, \sigma_{2}\right)$ is $(1,2)^{*}$-fuzzy soft b-continuous, then $(\phi, \psi)\left((1,2)^{*}-f s c l\left(f_{E}\right)\right) \widetilde{\subseteq} \tau_{1} \tau_{2} f s c l\left((\phi, \psi)\left(f_{E}\right)\right)$ for every $f_{E}$ in $\left(X, E, \tau_{1}, \tau_{2}\right)$.

Proof. Assume that $(\phi, \psi)$ is $(1,2)^{*}$-fuzzy soft $b$-continuous and $f_{E}$ be any fuzzy soft subset in $\left(X, E, \tau_{1}, \tau_{2}\right)$. Then $\tau_{1} \tau_{2} f s c l\left((\phi, \psi)\left(f_{E}\right)\right)$ is a $\sigma_{1} \sigma_{2}$-fuzzy soft closed set in $(Y, K$, $\left.\sigma_{1}, \sigma_{2}\right)$. Since $(\phi, \psi)$ is $(1,2)^{*}$-fuzzy soft $b$-continuous, $(\phi, \psi)^{-1}\left(\tau_{1} \tau_{2} f s c l\left((\phi, \psi)\left(f_{E}\right)\right)\right)$ is (1, $2)^{*}$-fuzzy soft $b$-closed set in $\left(X, E, \tau_{1}, \tau_{2}\right)$ and it contains $f_{E}$. But $(1,2)^{*}-f s c l\left(f_{E}\right)$ is the intersection of all $(1,2)^{*}$-fuzzy soft $b$-closed sets containing $f_{E}$. Therefore $(1,2)^{*}$ $f_{\operatorname{sbcl}}\left(f_{E}\right) \tilde{\subseteq}(\phi, \psi)^{-1}\left(\tau_{1} \tau_{2} f_{s c l}\left((\phi, \psi)\left(f_{E}\right)\right)\right)$ and so $(\phi, \psi)\left((1,2)^{*}-f_{s b c l}\left(f_{E}\right)\right) \tilde{\subseteq}$ $\tau_{1} \tau_{2} f \operatorname{scl}\left((\phi, \psi)\left(f_{E}\right)\right)$ for every fuzzy soft subset $f_{E}$ in $\left(X, E, \tau_{1}, \tau_{2}\right)$.

Remark 3.14 The composition of two $(1,2)^{*}$-fuzzy soft b-continuous maps need not be $(1,2)^{*}$-fuzzy soft b-continuous as is shown in the following example.

Example 3.15 Let $X=Y=Z=\{x, y\}, E=K=T=\left\{e_{1}, e_{2}\right\}$.

Let $\tau_{\mathbf{1}}=\left\{\widetilde{0}_{E}, \widetilde{1}_{E}, f_{1_{E}}\right\}, \tau_{2}=\left\{\widetilde{0}_{E}, \widetilde{1}_{E}, f_{2_{E}}\right\}$, where

$f_{1_{E}}=\left\{f_{1}\left(e_{1}\right)=\{x / 0.5, y / 0.0\}, f_{1}\left(e_{2}\right)=\{x / 0.0, y / 0.0\}=\widetilde{0}\right\}$,

$f_{2_{E}}=\left\{f_{2}\left(e_{1}\right)=\{x / 0.0, y / 0.7\}, f_{2}\left(e_{2}\right)=\{x / 0.0, y / 0.0\}=\tilde{0}\right\}$,

It is clear that $\left(X, E, \tau_{1}, \tau_{2}\right)$ is a fuzzy soft bitopological space.

The $\tau_{1} \tau_{2}$-fuzzy soft open sets are $\left\{\widetilde{0}_{E}, \tilde{1}_{E}, f_{1_{E}}, f_{2_{E}}, f_{3 E}\right\}$ where

$f_{3_{E}}=f_{\mathbf{1}_{E}} \tilde{\cup} f_{2_{E}}=\left\{f_{3}\left(e_{1}\right)=\{x \wedge .5, y / 0.7\}, f_{3}\left(e_{2}\right)=\{x \wedge .0, y / 0.0\}=\tilde{0}\right\}$, and $(1,2)^{*}$-fuzzy soft b-open sets are $\left\{\widetilde{0}_{E}, \tilde{1}_{E}, f_{\mathbf{1}_{E}}, f_{2_{E}}, f_{3_{E}}, f_{4_{E}}, f_{5 E}, f_{6_{E}}, f_{7_{E}}, f_{8_{E}}, f_{9_{E}}, f_{10_{E}}, f_{11_{E}}\right\}$, where

$f_{1_{E}}, f_{2_{E}}, f_{3_{E}}$ are shown as above and

$f_{4 E}=\left\{f_{4}\left(e_{1}\right)=\{x / 0.5, y / 0.0\}, f_{4}\left(e_{2}\right)=\{x / 0.3, y / 0.0\}\right\}$,

$f_{5_{E}}=\left\{f_{5}\left(e_{1}\right)=\{x / 0.5, y / 0.0\}, f_{5}\left(e_{2}\right)=\{x / 0.0, y / 0.6\}\right\}$,

$f_{6_{E}}=\left\{f_{6}\left(e_{1}\right)=\{x / 0.5, y / 0.0\}, f_{6}\left(e_{2}\right)=\{x / 0.3, y / 0.6\}\right\}$,

$f_{7_{E}}=\left\{f_{7}\left(e_{1}\right)=\{x / 0.0, y / 0.7\}, f_{7}\left(e_{2}\right)=\{x / 0.3, y / 0.0\}\right\}$,

$f_{8_{E}}=\left\{f_{8}\left(e_{1}\right)=\{x / 0.0, y / 0.7\}, f_{8}\left(e_{2}\right)=\{x / 0.0, y / 0.6\}\right\}$,

$f_{9_{E}}=\left\{f_{9}\left(e_{1}\right)=\{x / 0.0, y / 0.7\}, f_{9}\left(e_{2}\right)=\{x / 0.3, y / 0.6\}\right\}$,

$f_{1 \mathrm{O}_{E}}=\left\{f_{10}\left(e_{1}\right)=\{x / 0.5, y / 0.7\}, f_{10}\left(e_{2}\right)=\{x / 0.3, y / 0.0\}\right\}$,

$f_{11_{E}}=\left\{f_{11}\left(e_{1}\right)=\{x / 0.5, y / 0.7\}, f_{11}\left(e_{2}\right)=\{x / 0.0, y / 0.6\}\right\}$.

Let $\sigma_{1}=\left\{\widetilde{0}_{K}, \widetilde{1}_{K}, g_{1_{K}}\right\}, \sigma_{2}=\left\{\widetilde{0}_{K}, \widetilde{1}_{K}, g_{2_{K}}\right\}$, where

$g_{1_{K}}=\left\{g_{1}\left(e_{1}\right)=\{x / 0.5, y / 0.0\}, g_{1}\left(e_{2}\right)=\{x / 0.0, y / 0.0\}=\widetilde{0}\right\}$,

$g_{2_{K}}=\left\{g_{2}\left(e_{1}\right)=\{x / 0.0, y / 0.7\}, g_{2}\left(e_{2}\right)=\{x / 0.3, y / 0.6\}\right\}$,

It is clear that $\left(Y, K, \sigma_{1}, \sigma_{2}\right)$ is a fuzzy soft bitopological space. The $\sigma_{1} \sigma_{2}$-fuzzy soft open sets are $\left\{\widetilde{0}_{K}, \tilde{1}_{K}, g_{1_{K}}, g_{2_{K}}\right\}$ and $(1,2)^{*}$-fuzzy soft b-open sets are

$\left\{\widetilde{0}_{K}, \tilde{1}_{K}, g_{1_{K}}, g_{2_{K}}, g_{3_{K}}, g_{4_{K}}, g_{5_{K}}, g_{6_{K}}, g_{7_{K}}, g_{8_{K}}, g_{9_{K}}, g_{10_{K}}, g_{11_{K}}, g_{12_{K}}, g_{13_{K}}, g_{14_{K}}\right\}$ where $g_{1_{K}}, g_{2_{K}}$ are shown as above,

$g_{3 K}=\left\{g_{3}\left(e_{1}\right)=\{x / 0.5, y / 0.7\}, g_{3}\left(e_{2}\right)=\{x / 0.0, y / 0.0\}=\tilde{0}\right\}$,

$g_{4_{K}}=\left\{g_{4}\left(e_{1}\right)=\{x / 0.0, y / 0.0\}=\widetilde{0}, g_{4}\left(e_{2}\right)=\{x / 0.3, y / 0.0\}\right\}$,

$g_{5 K}=\left\{g_{5}\left(e_{1}\right)=\{x / 0.0, y / 0.0\}=\widetilde{0}, g_{5}\left(e_{5}\right)=\{x / 0.0, y / 0.6\}\right\}$,

$g_{6_{K}}=\left\{g_{6}\left(e_{1}\right)=\{x / 0.0, y / 0.0\}=\widetilde{0}, g_{6}\left(e_{2}\right)=\{x / 0.3, y / 0.6\}\right\}$,

$g_{7 K}=\left\{g_{7}\left(e_{1}\right)=\{x / 0.5, y / 0.0\}, g_{7}\left(e_{2}\right)=\{x / 0.3, y / 0.0\}\right\}$,

$g_{8_{K}}=\left\{g_{8}\left(e_{1}\right)=\{x / 0.5, y / 0.0\}, g_{8}\left(e_{2}\right)=\{x / 0.0, y / 0.6\}\right\}$,

$g_{9_{K}}=\left\{g_{9}\left(e_{1}\right)=\{x / 0.5, y / 0.0\}, g_{9}\left(e_{2}\right)=\{x / 0.3, y / 0.6\}\right\}$, 
$g_{10_{K}}=\left\{g_{10}\left(e_{1}\right)=\{x / 0.0, y / 0.7\}, g_{10}\left(e_{5}\right)=\{x / 0.3, y / 0.0\}\right\}$,

$g_{11_{K}}=\left\{g_{1}\left(e_{11}\right)=\{x / 0.0, y / 0.7\}, g_{11}\left(e_{2}\right)=\{x / 0.0, y / 0.6\}\right\}$,

$g_{12_{K}}=\left\{g_{12}\left(e_{1}\right)=\{x / 0.0, y / 0.7\}, g_{12}\left(e_{2}\right)=\{x / 0.3, y / 0.6\}\right\}$,

$g_{13_{K}}=\left\{g_{13}\left(e_{1}\right)=\{x / 0.5, y / 0.7\}, g_{13}\left(e_{2}\right)=\{x / 0.3, y / 0.0\}\right\}$,

$g_{14_{K}}=\left\{g_{14}\left(e_{1}\right)=\{x / 0.5, y / 0.7\}, g_{14}\left(e_{2}\right)=\{x / 0.0, y / 0.6\}\right\}$.

Let $\eta_{1}=\left\{0_{T}, 1_{T}, h_{\mathbf{1}_{T}}, h_{2_{T}}, h_{3 T}\right\}, \eta_{2}=\left\{\widetilde{0}_{T}, \widetilde{1}_{T}, h_{4_{T}}, h_{5 T}\right\}$, where

$h_{1_{T}}=\left\{h_{1}\left(e_{1}\right)=\{x / 0.5, y / 0.0\}, h_{1}\left(e_{2}\right)=\{x / 0.0, y / 0.0\}=\tilde{0}\right\}$,

$h_{2_{T}}=\left\{h_{2}\left(e_{1}\right)=\{x / 0.5, y / 0.0\}, h_{2}\left(e_{2}\right)=\{x / 0.3, y / 0.0\}\right\}$,

$h_{3 T}=\left\{h_{3}\left(e_{1}\right)=\{x / 0.5, y / 0.7\}, h_{3}\left(e_{2}\right)=\{x / 0.3, y / 0.0\}\right\}$,

$h_{4 T}=\left\{h_{4}\left(e_{1}\right)=\{x / 0.0, y / 0.0\}=\widetilde{0}, h_{4}\left(e_{2}\right)=\{x / 0.3, y / 0.0\}\right\}$,

$h_{5 T}=\left\{h_{5}\left(e_{1}\right)=\{x / 0.5, y / 0.0\}, h_{5}\left(e_{2}\right)=\{x / 0.0, y / 0.6\}=\widetilde{0}\right\}$.

It is clear that $\left(Z, T, \eta_{1}, \eta_{2}\right)$ is a fuzzy soft bitopological space. The $\eta_{1} \eta_{2}$-fuzzy soft open sets are $\left\{\widetilde{0}_{T}, \tilde{1}_{T}, h_{1_{T}}, h_{2_{T}}, h_{3 T}, h_{4 T}, h_{5 T}\right\}$ and $(1,2)^{*}$-fuzzy soft b-open sets are

$\left\{\widetilde{0}_{T}, \tilde{1}_{T}, h_{1_{T}}, h_{2_{T}}, h_{3 T}, h_{4_{T}}, h_{5 T}, h_{6_{T}}, H_{7_{T}}, h_{8_{T}}, H_{9_{T}}\right\}$ where $h_{1_{T}}, h_{2_{T}}, h_{3 T}, h_{4_{T}}, h_{5_{T}}$ are shown as above,

$h_{6_{T}}=\left\{h_{1}\left(e_{1}\right)=\{x / 0.5, y / 0.0\}, h_{1}\left(e_{2}\right)=\{x / 0.3, y / 0.6\}\right\}$,

$h_{7 T}=\left\{h_{2}\left(e_{1}\right)=\{x / 0.0, y / 0.7\}, h_{2}\left(e_{2}\right)=\{x / 0.3, y / 0.0\}\right\}$,

$h_{8_{T}}=\left\{h_{3}\left(e_{1}\right)=\{x / 0.0, y / 0.7\}, h_{3}\left(e_{2}\right)=\{x / 0.0, y / 0.6\}\right\}$,

$h_{9 T}=\left\{h_{4}\left(e_{1}\right)=\{x / 0.0, y / 0.7\}, h_{4}\left(e_{2}\right)=\{x / 0.3, y / 0.6\}\right\}$,

and $(\phi, \psi):\left(X, E, \tau_{1}, \tau_{2}\right) \rightarrow\left(Y, K, \sigma_{1}, \sigma_{2}\right)$ and $(\phi, \dot{\psi}):\left(Y, K, \sigma_{1}, \sigma_{2}\right) \rightarrow\left(Z, T, \eta_{1}, \eta_{2}\right)$ are defined as identity mappings. Hence $(\phi, \psi)$ and $(\phi, \dot{\psi})$ are $(1,2)^{*}$-fuzzy soft b-continuous since $((\not{\phi}, \dot{\psi}) \circ(\phi, \psi))^{-1}\left(h_{5 T}\right)$ which is not a $(1,2)^{*}$-fuzzy soft b-open set in $\left(X, E, \tau_{1}, \tau_{2}\right)$.

Theorem 3.16 Let $(\phi, \psi):\left(X, E, \tau_{1}, \tau_{2}\right) \rightarrow\left(Y, K, \sigma_{1}, \sigma_{2}\right)$ and $(\not, \bar{\psi}):\left(Y, K, \sigma_{1}, \sigma_{2}\right) \rightarrow$ $\left(Z, T, \eta_{1}, \eta_{2}\right)$ be two maps in fuzzy soft bitopological spaces. Then

$(\phi, \psi)_{\circ}(\phi, \psi):\left(X, E, \tau_{1}, \tau_{2}\right) \rightarrow\left(Z, T, \eta_{1}, \eta_{2}\right)$ is $(1,2)^{*}$-fuzzy soft b-continuous, if $(\phi, \psi)$ is $(1,2)^{*}$-fuzzy soft $b$-continuous and $(\phi, \dot{\psi})$ is $(1,2)^{*}$-fuzzy soft $b$-continuous.

Proof. Let $h_{T}$ be a $\eta_{1} \eta_{2}$-fuzzy soft closed set of $\left(Z, T, \sigma_{1}, \sigma_{2}\right)$. Since $(\not, \dot{\psi}):\left(Y, K, \sigma_{1}\right.$, $\left.\sigma_{2}\right) \rightarrow\left(Z, T, \eta_{1}, \eta_{2}\right)$ is $(1,2)^{*}$-fuzzy soft $b$-continuous, then $(\phi, \dot{\psi})^{-1}\left(h_{T}\right)$ is $\sigma_{1} \sigma_{2}$-fuzzy soft closed set in $\left(Y, K, \sigma_{1}, \sigma_{2}\right)$. Now $(\phi, \psi):\left(X, E, \tau_{1}, \tau_{2}\right) \rightarrow\left(Y, K, \sigma_{1}, \sigma_{2}\right)$ is $(1,2)^{*}$-fuzzy soft $b$-continuous and $(\phi, \dot{\psi})^{-1}\left(h_{T}\right)$ is $\sigma_{1} \sigma_{2}$-fuzzy soft closed set in $\left(Y, K, \sigma_{1}, \sigma_{2}\right)$, then $(\phi, \psi)^{-1}\left[(\not, \bar{\psi})^{-1}\left(h_{T}\right)\right]=((\not, \dot{\psi}) \circ(\phi, \psi))^{-1}\left(h_{T}\right)$ is $(1,2)^{*}$-fuzzy soft $b$-closed in $\left(X, E, \tau_{1}, \tau_{2}\right)$. Hence $(\phi, \bar{\psi}) \circ(\phi, \psi):\left(X, E, \tau_{1}, \tau_{2}\right) \rightarrow\left(Z, T, \eta_{1}, \eta_{2}\right)$ is $(1,2)^{*}$-fuzzy soft $b$-continuous.

\section{$4(1,2) *$-fuzzy soft $b$-irresolute maps}

In this section we introduce the concept of $(1,2)^{*}$-fuzzy soft $b$-irresolute maps and discuss the relation with $(1,2)^{*}$-fuzzy soft $b$-continuous maps.

Definition 4.1 A fuzzy soft mapping $(\phi, \psi):\left(X, E, \tau_{1}, \tau_{2}\right) \quad\left(, Y, K, \sigma_{1}, \sigma_{2}\right)$ is said to be (1, 2)*-fuzzy soft b-irresolute mapping (briefly, $(1,2)^{*}-f$ sb-irresolute) if $(\phi, \psi)^{-1}\left(g_{K}\right)$ is a $(1$, $2)^{*}$-fuzzy soft b-closed set in $\left(X, E, \tau_{1}, \tau_{2}\right)$ for every $(1,2)^{*}$-fuzzy soft b-closed set $g_{K}$ in $(Y$, 
Bulletin of the

Korean Mathematical Society

ISSN 1015-8634 (Print) ISSN22343016 (Online)

$\left.K, \sigma_{1}, \sigma_{2}\right)$. 
Theorem 4.2 A fuzzy soft mapping $(\phi, \psi):\left(X, E, \tau_{1}, \tau_{2}\right) \quad\left(Y, K, \sigma_{1}, \sigma_{2}\right)$ is $(1,2)^{*}$-fuzzy soft $b$-irresolute mapping if and only if the inverse image of every $(1,2)^{*}$-fuzzy soft b-openset in $\left(Y, K, \sigma_{1}, \sigma_{2}\right)$ is $(1,2)^{*}$-fuzzy soft $b$-open set in $\left(X, E, \tau_{1}, \tau_{2}\right)$.

Proof. $\Rightarrow$ : Let $g_{K}$ be a $(1,2)^{*}$-fuzzy soft $b$-open set in $\left(Y, K, \sigma_{1}, \sigma_{2}\right)$. Then $g_{K}^{c}$ is a $(1,2)^{*}$-fuzzy soft $b$-closed set in $\left(Y, K, \sigma_{1}, \sigma_{2}\right)$. Thus $(\phi, \psi)^{-1}\left(g^{c}{ }_{K}\right)$ is a $(1,2)^{*}$-fuzzy soft $b$-closed set in $\left(X, E, \tau_{1}, \tau_{2}\right)$. But $(\phi, \psi)^{-1}\left(g_{K}^{c}\right)=\left[(\phi, \psi)^{-1}\left(g_{K}\right)\right]^{c}$, so that $(\phi, \psi)^{-1}\left(g_{K}\right)$ is $(1,2)^{*}$-fuzzy soft $b$-open set in $\left(X, E, \tau_{1}, \tau_{2}\right)$.

$\Leftarrow$ : Let $g_{K}$ be a $(1,2)^{*}$-fuzzy soft $b$-closed set in $\left(Y, K, \sigma_{1}, \sigma_{2}\right)$. Then $g_{K}^{c}$ is a $(1,2)^{*}$ fuzzy soft $b$-open set in $\left(Y, K, \sigma_{1}, \sigma_{2}\right)$. Thus $(\phi, \psi)^{-1}\left(g^{c}{ }_{k}\right)$ is $(1,2)^{*}$-fuzzy soft $b$-open set in $\left(X, E, \tau_{1}, \tau_{2}\right)$. Also $(\phi, \psi)^{-1}\left(g_{K}^{c}\right)=\left[(\phi, \psi)^{-1}\left(g_{K}\right)\right]^{c}$. Thus $(\phi, \psi)^{-1}\left(g_{K}\right)$ is $(1,2)^{*}$-fuzzy soft $b$-closed set in $\left(X, E, \tau_{1}, \tau_{2}\right)$. Therefore $(\phi, \psi):\left(X, E, \tau_{1}, \tau_{2}\right) \rightarrow\left(Y, K, \sigma_{1}, \sigma_{2}\right)$ is $(1,2)^{*}$ fuzzy soft $b$-irresolute mapping.

Theorem 4.3 Every $(1,2)^{*}$-fuzzy soft $b$-irresolute mapping is $(1,2)^{*}$-fuzzy soft $b$-continuous.

Proof. Let $(\phi, \psi):\left(X, E, \tau_{1}, \tau_{2}\right)\left(Y, K, \sigma_{1}, \sigma_{2}\right)$ be a $(1,2)^{*}$-fuzzy soft $b$-irresolute mapping. Let $g_{K}$ be $\sigma_{1} \sigma_{2}$-fuzzy soft closed set in $\left(Y, K, \sigma_{1}, \sigma_{2}\right)$, then $g_{K}$ is a $(1,2)^{*}$-fuzzy soft $b$-closed set in $\left(Y, K, \sigma_{1}, \sigma_{2}\right)$. Since $(\phi, \psi)$ is a $(1,2)^{*}$-fuzzy soft $b$-irresolute mapping, $(\phi, \psi)\left(g_{K}\right)$ is $(1$, $2)^{*}$-fuzzy soft $b$-closed set in $\left(X, E, \tau_{1}, \tau_{2}\right)$. Therefore $(\phi, \psi)$ is a $(1,2)^{*}$ - fuzzy soft $b$ continuous.

The converse of the above theorem is not true as is shown in the following example.

Example 4.4 Consider the Example 3.3, $(\phi, \psi):\left(X, E, \tau_{1}, \tau_{2}\right) \rightarrow\left(Y, K, \sigma_{1}, \sigma_{2}\right)$ is $(1,2)^{*}-$ fuzzy soft $b$-continuous but not $(1,2)^{*}$-fuzzy soft $b$-irresolute mapping.

Theorem 4.5 Let $(\phi, \psi):\left(X, E, \tau_{1}, \tau_{2}\right) \rightarrow\left(Y, K, \sigma_{1}, \sigma_{2}\right)$ and $(\phi, \grave{\psi}):\left(Y, K, \sigma_{1}, \sigma_{2}\right) \rightarrow$ $\left(Z, T, \eta_{1}, \eta_{2}\right)$ be two maps in fuzzy soft bitopological spaces. Then $(\not{\phi}, \bar{\psi}) \circ(\phi, \psi)$ :

$\left(X, E, \tau_{1}, \tau_{2}\right) \rightarrow\left(Z, T, \eta_{1}, \eta_{2}\right)$ is

(i) $(1,2)^{*}$-fuzzy soft b-irresolute, if $(\phi, \psi)$ and $(\not, \dot{\psi})$ are $(1,2)^{*}$-fuzzy soft b-irresolute maps.

(ii) $(1,2)^{*}$-fuzzy soft b-continuous, if $(\phi, \psi)$ is $(1,2)^{*}$-fuzzy soft b-irresolute and $(\not, \bar{\psi})$ is $(1,2)^{*}$-fuzzy soft b-continuous.

Proof. (i) Let $(\not, \bar{\psi}):\left(Y, K, \sigma_{1}, \sigma_{2}\right) \rightarrow\left(Z, T, \eta_{1}, \eta_{2}\right)$ is $(1,2)^{*}$-fuzzy soft $b$-irresolute and $h_{T}$ be $(1,2)^{*}$-fuzzy soft $b$-closed set of $\left(Z, T, \eta_{1}, \eta_{2}\right)$. Since $(\not, \bar{\psi})$ is $(1,2)^{*}$-fuzzy soft $b$-irresolute; $(\not, \bar{\psi})^{-1}\left(h_{T}\right)$ is $(1,2)^{*}$-fuzzy soft $b$-closed set of $\left(Y, K, \sigma_{1}, \sigma_{2}\right)$. Also $(\phi, \psi)$ : $\left(X, E, \tau_{1}, \tau_{2}\right) \rightarrow\left(Y, K, \sigma_{1}, \sigma_{2}\right)$ is $(1,2)^{*}$-fuzzy soft $b$-irresolute. So $(\phi, \psi)^{-1}\left[\left(\not, \bar{\psi}^{-1}\left(h_{T}\right)\right]=\right.$ $\left((\not, \psi) \circ(\phi, \psi):\left(X, E, \tau_{1}, \tau_{2}\right) \rightarrow\left(Z, T, \eta_{1}, \eta_{2}\right)\right)^{-1}\left(h_{T}\right)$ is $(1,2)^{*}$-fuzzy soft $b$-closed set in $\left(X, E, \tau_{1}, \tau_{2}\right)$. Thus $(\not{\phi}, \dot{\psi}) \circ(\phi, \psi):\left(X, E, \tau_{1}, \tau_{2}\right) \rightarrow\left(Z, T, \eta_{1}, \eta_{2}\right)$ is a $(1,2)^{*}$-fuzzy soft $b$-irresolute.

(ii) Let $h_{T}$ be a $\eta_{1} \eta_{2}$-fuzzy soft closed subset of $\left(Z, T, \eta_{1}, \eta_{2}\right)$. Since $(\not{\phi}, \grave{\psi}):\left(Y, K, \sigma_{1}, \sigma_{2}\right) \rightarrow$ $\left(Z, T, \eta_{1}, \eta_{2}\right)$ is $(1,2)^{*}$-fuzzy soft $b$-continuous, then $(\not{\phi}, \dot{\psi})^{-1}\left(h_{T}\right)$ is $(1,2)^{*}$-fuzzy soft $b$ closed set of $\left(Y, K, \sigma_{1}, \sigma_{2}\right)$. Also $(\phi, \psi):\left(X, E, \tau_{1}, \tau_{2}\right) \rightarrow\left(Y, K, \sigma_{1}, \sigma_{2}\right)$ is $(1,2)^{*}$-fuzzy soft 
$b$-irresolute. So every $(1,2)^{*}$-fuzzy soft $b$-closed set of $\left(Y, K, \sigma_{1}, \sigma_{2}\right)$ is $(1,2)^{*}$-fuzzy soft $b$ closed set of $\left(X, E, \tau_{1}, \tau_{2}\right)$. Hence $(\phi, \psi)^{-1}\left[(\phi, \dot{\psi})^{-1}\left(h_{T}\right)\right]=((\phi, \dot{\psi}) \mathrm{o}(\phi, \psi))^{-1}\left(h_{T}\right)$ is $(1,2)^{*}-$ fuzzy soft $b$-closed set in $\left(X, E, \tau_{1}, \tau_{2}\right)$. Hence $(\phi, \psi) \circ(\phi, \psi):\left(X, E, \tau_{1}, \tau_{2}\right) \rightarrow\left(Z, T, \eta_{1}, \eta_{2}\right)$ is $(1,2)^{*}$-fuzzy soft $b$-continuous.

\section{$5(1,2)^{*}$-fuzzy soft $b$-open(closed) maps}

In this section, we introduce and discuss the characterization of $(1,2)^{*}$-fuzzy soft $b$ open(closed) maps and studied some of their properties.

Definition 5.1 A fuzzy soft map $(\phi, \psi):\left(X, E, \tau_{1}, \tau_{2}\right) \rightarrow\left(Y, K, \sigma_{1}, \sigma_{2}\right)$ is said to be (i) a (1,2)*-fuzzy soft b-open (briefly, (1,2)*-fsb-open) map if the image of every $(1,2)^{*}$ fuzzy soft b-open set in $\left(X, E, \tau_{1}, \tau_{2}\right)$ is $(1,2)^{*}$-fuzzy soft b-open set in $\left(Y, K, \sigma_{1}, \sigma_{2}\right)$. (ii) a (1,2)*-fuzzy soft b-closed (briefly, $(1,2)^{*}$-fsb-closed) map if the image of every $(1,2)^{*}$-fuzzy soft b-closed set in $\left(X, E, \tau_{1}, \tau_{2}\right)$ is $(1,2)^{*}$-fuzzy soft $b$-closed set in $\left(Y, K, \sigma_{1}, \sigma_{2}\right)$.

Theorem 5.2 If $(\phi, \psi):\left(X, E, \tau_{1}, \tau_{2}\right) \rightarrow\left(Y, K, \sigma_{1}, \sigma_{2}\right)$ is $(1,2)^{*}$-fuzzy soft b-closed map and $(\not, \dot{\psi}):\left(Y, K, \sigma_{1}, \sigma_{2}\right) \rightarrow\left(Z, T, \eta_{1}, \eta_{2}\right)$ is $(1,2)^{*}$-fuzzy soft b-closed map. Then $(\bar{\phi}, \dot{\psi}) \circ$ $(\phi, \psi):\left(X, E, \tau_{1}, \tau_{2}\right) \rightarrow\left(Z, T, \eta_{1}, \eta_{2}\right)$ is $(1,2)^{*}$-fuzzy soft b-closed map.

Proof. Let $f_{E}$ be $(1,2)^{*}$-fuzzy soft closed set in $\left(X, E, \tau_{1}, \tau_{2}\right),(\phi, \psi)\left(f_{E}\right)$ is $\sigma_{1} \sigma_{2}$-fuzzy soft closed set in $\left(Y, K, \sigma_{1}, \sigma_{2}\right)$. Since $(\not, \bar{\psi}):\left(Y, K, \sigma_{1}, \sigma_{2}\right) \quad\left(Z, T, \eta_{1}, \eta_{2}\right)$ is $(1,2)^{*}$-fuzzy soft $b$-closed map, $(\not, \bar{\psi})\left((\phi, \psi)\left(f_{E}\right)\right)$ is $(1,2)^{*}$-fuzzy soft closed set in $\left(Z, T, \eta_{1}, \eta_{2}\right)$ and $(\not{\phi}$, $\dot{\psi})\left((\phi, \psi)\left(f_{E}\right)\right)=(\phi, \psi) \quad(\phi, \psi)\left(f_{E}\right)$. Therefore $(\phi, \dot{\psi}) \quad(\phi, \psi)$ is $(1,2)^{*}$-fuzzy soft $b$ closed map.

Theorem 5.3 Let $(\phi, \psi):\left(X, E, \tau_{1}, \tau_{2}\right) \rightarrow\left(Y, K, \sigma_{1}, \sigma_{2}\right)$ and $(\phi, \dot{\psi}):\left(Y, K, \sigma_{1}, \sigma_{2}\right) \rightarrow$ $\left(Z, T, \eta_{1}, \eta_{2}\right)$ be two fuzzy soft maps such that $(\not, \dot{\psi}) \circ(\phi, \psi)$ is $(1,2)^{*}$-fuzzy soft b-closed map.

(i) If $(\phi, \psi)$ is a $(1,2)^{*}$-fuzzy soft continuous and surjective, then $(\phi, \dot{\psi})$ is $(1,2)^{*}$-fuzzy b-closed map.

(ii) If $(\phi, \dot{\psi})$ is $(1,2)^{*}$-fuzzy soft b-irresolute and injective, then $(\phi, \psi)$ is a $(1,2)^{*}$-fuzzy soft $b$-closed map.

Proof. (i) Let $g_{K}$ be $\sigma_{1} \sigma_{2}$-fuzzy soft closed set in $\left(Y, K, \sigma_{1}, \sigma_{2}\right)$. If $(\phi, \psi)$ is a $(1,2)^{*}$-fuzzy soft continuous and surjective, then $(\phi, \psi)^{-1}\left(g_{K}\right)$ is a $\tau_{1} \tau_{2}$-fuzzy $\operatorname{soft}$ closed set in $(X, E$, $\left.\tau_{1}, \tau_{2}\right)$. Since $(\phi, \dot{\psi}) \quad(\phi, \psi)_{0}$ is $(1,2)^{*}$-fuzzy soft $b$-closed map,

$(\not, \psi) \circ(\phi, \psi)\left((\phi, \psi)^{-1}\left(g_{K}\right)\right)=(\phi, \psi)\left(g_{K}\right)$ is $(1,2)^{*}$-fuzzy soft $b$-closed map in $\left(Z, T, \eta_{1}, \eta_{2}\right)$. Hence $(\not, \bar{\psi}):\left(Y, K, \sigma_{1}, \sigma_{2}\right) \rightarrow\left(Z, T, \eta_{1}, \eta_{2}\right)$ is $(1,2)^{*}$-fuzzy soft $b$-closed map.

(ii) Let $f_{E}$ be $\tau_{1} \tau_{2}$-fuzzy soft closed subset of $\left(X, E, \tau_{1}, \tau_{2}\right)$. If $(\not{\phi}, \bar{\psi}) \mathrm{d}(\phi, \psi):\left(X, E, \tau_{1}, \tau_{2}\right) \rightarrow$ $\left(Z, T, \eta_{1}, \eta_{2}\right)$ is $(1,2)^{*}$-fuzzy soft $b$-closed map; then $(\phi, \psi)$ o $(\phi, \psi)\left(f_{E}\right)$ is a $(1,2)^{*}$-fuzzy soft $b$-closed set in $\left(Z, T, \eta_{1}, \eta_{2}\right)$, and so $(\not, \bar{\psi})^{-1}((\not, \bar{\psi}) \circ(\phi, \psi))\left(f_{E}\right)=(\phi, \psi)\left(f_{E}\right)$ is $(1,2)^{*}$ fuzzy soft $b$-closed set in $\left(Y, K, \sigma_{1}, \sigma_{2}\right)$. Since $(\phi, \psi)$ is $(1,2)^{*}$-fuzzy soft $b$-irresolute and injective, then $(\phi, \psi)$ is a $(1,2)^{*}$-fuzzy soft $b$-closed map. 
Proposition 5.4 For any bijection fuzzy $\operatorname{soft} \operatorname{map}(\phi, \psi):\left(X, E, \tau_{1}, \tau_{2}\right) \rightarrow\left(Y, K, \sigma_{1}, \sigma_{2}\right)$ the following statements are equivalent.

(i) The inverse fuzzy soft map $(\phi, \psi)^{-1}:\left(Y, K, \sigma_{1}, \sigma_{2}\right) \rightarrow\left(X, E, \tau_{1}, \tau_{2}\right)$ is $(1,2)^{*}$-fuzzy soft b-continuous.

(ii) $(\phi, \psi)$ is $(1,2)^{*}$-fuzzy soft b-open map.

(iii) $(\phi, \psi)$ is $(1,2)^{*}$-fuzzy soft b-closed map.

Proof. $(i) \Rightarrow(i i)$ : Given that $(\phi, \psi)^{-1}:\left(Y, K, \sigma_{1}, \sigma_{2}\right) \rightarrow\left(X, E, \tau_{1}, \tau_{2}\right)$ is $(1,2)^{*}$ - fuzzy soft $b$-continuous. Let $f_{E}$ be a $\tau_{1} \tau_{2}$-fuzzy soft open set in $\left(X, E, \tau_{1}, \tau_{2}\right)$. Then $((\phi$, $\left.\psi)^{-1}\right)^{-1}\left(f_{E}\right)=(\phi, \psi)\left(f_{E}\right)$ is $(1,2)^{*}$-fuzzy soft $b$-open set in $\left(Y, K, \sigma_{1}, \sigma_{2}\right)$.

(ii) $\Rightarrow($ iii $)$ : Let $(\phi, \psi):\left(X, E, \tau_{1}, \tau_{2}\right) \rightarrow\left(Y, K, \sigma_{1}, \sigma_{2}\right)$ be a $(1,2)^{*}$-fuzzy soft $b$-open map. Let $f_{E}$ be a $\tau_{1} \tau_{2}$-fuzzy soft open set in $\left(X, E, \tau_{1}, \tau_{2}\right)$. Then $f^{c}{ }_{E}$ be a $\tau_{1} \tau_{2}$-fuzzy soft closed set in $\left(X, E, \tau_{1}, \tau_{2}\right)$. Thus $(\phi, \psi)\left(f^{c}\right)_{E}(1,2)^{*}$-fuzzy soft $b$-closed set in $\left(Y, K, \sigma_{1}, \sigma_{2}\right)$. Therefore $(\phi, \psi)$ is $(1,2)^{*}$-fuzzy soft $b$-closed map.

(iii) $\Rightarrow(i)$ : Let $(\phi, \psi)$ is a $(1,2)^{*}$-fuzzy soft $b$-closed map. Let $f_{E}$ be a $\tau_{1} \tau_{2}$-fuzzy soft closed set in $\left(X, E, \tau_{1}, \tau_{2}\right)$, then $\left((\phi, \psi)^{-1}\right)^{-1}\left(f_{E}\right)=(\phi, \psi)\left(f_{E}\right)$ is $(1,2)^{*}$-fuzzy soft $b$-closedset in $\left(Y, K, \sigma_{1}, \sigma_{2}\right)$. Therefore $(\phi, \psi)^{-1}:\left(Y, K, \sigma_{1}, \sigma_{2}\right)\left(X, E, \tau_{1}, \tau_{2}\right)$ is $(1,2)^{*}$-fuzzy soft $b$ continuous.

\section{Conclusion}

In this paper, we introduced the concepts of $(1,2)^{*}$-fuzzy soft $b$-continuous maps, $(1,2)^{*}$ - fuzzy soft $b$-irresolute maps and the relations with other weak forms of fuzzy soft con- tinuous maps in fuzzy soft bitopological spaces. Also we introduced and investigated the basic properties of $(1,2)^{*}$-fuzzy soft $b$-irresolute map and $(1,2)^{*}$-fuzzy soft $b$-open (closed) maps. We hope that this paper will be important for researchers to studying many other concepts and also the generalization for some important results in topology.

\section{Compliance with ethical standards}

Funding There is no specific funding for this article, and it has been done under the general rules of the research department of the university of Umm Al-Qura

Conflict of interest The author declares that there is no conflict of interests regarding the publication of this paper.

Ethical approval This article does not contain any studies with human participants or animals performed by the author. 


\section{References}

[1] A. Açıkgöz and N. A. Taş, Some new mixed soft sets, Math. Sci. Appl. E-Notes, 2 (2) (2014), 105-118. 1

[2] A. Açıkgöz, N. A. Taş and T. Noiri, A decomposition of some types of mixed soft continuity in soft topological spaces, Filomat, 30 (2) (2016), 379-385. 1

[3] A. Aygünolu and H. Aygün, Introduction to fuzzy soft groups, Computers and Mathematics with Applications, 58(2009), 1279-1286. 2.31

[4] T. Beaulaa and C. Gunaseelib, On fuzzy soft metric spaces, Malaya J. Mat.,44(8-9) (2014), 197-202. 2.12

[5] D. Chen, The parametrization reduction of soft sets and its applications, Comput. Math. Appl., 49 (2005), 757-763. 1

[6] C. C. Chou, J. M. Yih, J. F. Ding, T. C. Han, Y. H. Lim, L. J. Liu and W. K. Hsu, Application of a fuzzy EOQ model to the stock management in the manufacture system,

Key Engineering Materials, 499 (2012), 361-365. 1

[7] C. Eksin, M. Güzelkaya, E. Yesil and I. Eksin, Fuzzy logic approach to mimic decision making behaviour of humans in stock management game, Proceedings of the 2008 System Dynamics Conference 2008. 1

[8] B. M. Ittanagi, Soft Bitopological Spaces, International Journal of Computer Applications, 107 (7) (2014), 1-4. 1

[9] A. Kandil, O. A. E. Tantawy, S. A. El-Sheikh, Shawqi A. Hazza, Pairwise open (closed) soft sets in soft bitopological spaces, Annals of Fuzzy Mathematics and Informatics, 11(4) (2016), 1-20. 1

[10] A. Kandil, O. A. E. Tantawy, S. A. El-Sheikh, Shawqi A. Hazza, Pairwise soft separation axioms in soft bitopological spaces, Annals of Fuzzy Mathematics and Informatics, 4 (4) (2016), 571-588. 1

[11] J. C. Kelly, Bitopological spaces, Proc. London Math. Soc., 13 (1963), 71-81. 1

[12] I. L. Reilly, On bitopological separation properties, Nanta Math., 29 (1972), 14-25. 1

[13] J. Mahanta and P.K. Das, Results on fuzzy soft topological spaces, arXiv:1203.0634V1, 2012. 2.10, 2.11

[14] P. K. Maji, R. Biswas and A. R. Roy, Fuzzy soft sets, Journal of Fuzzy Mathematics, 9(3) (2001)589-602. 2.4

[15] P. K. Maji, R. Biswas, R. Roy, Soft set theory, Comput. Math. Appl., 45 (2003), 555-562. $1,2.5$

[16] D.A. Molodtsov, Soft set theory-first results, Comput. Math. Appl., 37 (1999), 19-31. 1, 2.3 
[17] N. Y. Özgür and N. Taş, A note on "application of fuzzy soft sets to investment decision making problem", Journal of New Theory, 1 (7) (2015), 1-10. 1

[18] T. Y. Öztürk and M. Karademr, Soft pair-wise b-continuity on soft bitopological spaces,Celal Bayar University Journal of Science, 13 (2)(2017), 413-422. 1

[19] Prakash Mukherjee1 and Choonkil Park, On fuzzy soft Bitopological spaces, Mathematics and Computer Sciences Journal (MCSJ), Vol. 10 No. 7 Jul (2015), 1-8. 1, 2.14, 2.15, 2.16, $2.17,2.18,2.19,2.20,2.21,2.22,2.23,2.24,2.25$

[20] C. W. Patty, Bitopological spaces, Duke Math. J., 34 (1967), 387- 392.1

[21] N. Revathi and K. Bageerathi, $(1,2)^{*}$-SOFT b-CONTINUOUS AND $(1,2){ }^{*}$-SOFT $b$ CLOSED MAP, Asian Journal of Mathematics and Computer Research, 17(2) (2017), 111122. 1

[22] N. Revathi and K. Bageerathi, On Soft B-Open Sets In Soft Bitopological Space, International Journal of Applied Research, 1(11) (2015), 615-623. 1

[23] S. E. Rodabaugh, Powerset Operator Foundations For Poslat Fuzzy Set Theories and Topologies, Chapter 2 in Mathematics of Fuzzy Sets: Logic, Topology and Measure Theory, U. Hhle and S.E. Rodabaugh eds. (Kluwer Academic Publishers, (1999), 91-116. 2

[24] S. Roy and T. K. Samanta, A note on fuzzy soft topological spaces, Annals of Fuzzy Mathematics and informatics, 3 (2) (2012), 305-311. 2.6, 2.7, 2.8, 2.9, 2.13

[25] A. F. Sayed, On fuzzy soft b-open sets in fuzzy soft bitopological space, J. Math. Computer Sci., 21 (2020), 3144. 1, 2.27, 2.28, 2.29, 2.30

[26] A. F. Sayed, Some separation axioms in fuzzy soft bitopological spaces, Journal of mathematical and computational science (JMCS), 8(1) (2018), 28-45. 1

[27] A. F. Sayed, On characterizations of some types of fuzzy soft Sets in fuzzy soft bitopological spaces, J. Adv. Math. Comput. Sci. 24 (3)(2017), 1-12, Article no.JAMCS.35969. 1, 2.26

[28] N. A. Taş and A. Alkgöz, Some mixed soft operations and extremally soft disconnectedness via two soft topologies, Appl. Math., 5 (2014), 490-500. 1

[29] S. Y. Yüksel, T. Dizman, G. Yildizdan and Ü. Sert, Application of soft sets to diagnose the prostate cancer risk, Journal of Inequalities and Applications, 2013(2013), 2013-229. 1

[30] L. A. Zadeh, Fuzzy sets, Information and Control, 8 (1965), 338-353. 1, 2.1, 2, 2.2 